\title{
A Hybrid Neural Network-Particle Swarm Optimization Informed Spatial Interpolation Technique for Groundwater Quality Mapping in a Small Island Province of the Philippines
}

\author{
Kevin Lawrence M. De Jesus ${ }^{1,2,3}$, Delia B. Senoro ${ }^{1,2,3,4, *(D)}$, Jennifer C. Dela Cruz ${ }^{1,5}$ and Eduardo B. Chan $^{6}$ \\ 1 School of Graduate Studies, Mapua University, Manila 1002, Philippines; \\ klmdejesus@mymail.mapua.edu.ph (K.L.M.D.J.); jcdelacruz@mapua.edu.ph (J.C.D.C.) \\ 2 School of Chemical, Biological, Materials Engineering and Sciences, Mapua University, \\ Manila 1002, Philippines \\ 3 Resiliency and Sustainable Development Center, Yuchengco Innovation Center, Mapua University, \\ Manila 1002, Philippines \\ 4 School of Civil, Environmental and Geological Engineering, Mapua University, Manila 1002, Philippines \\ 5 School of Electrical, Electronics and Computer Engineering, Mapua University, Manila 1002, Philippines \\ 6 Dyson College of Arts and Science, Pace University, New York, NY 10038, USA; echan@pace.edu \\ * Correspondence: dbsenoro@mapua.edu.ph; Tel.: +63-2-8251-6622
}

Citation: De Jesus, K.L.M.; Senoro, D.B.; Dela Cruz, J.C.; Chan, E.B. A Hybrid Neural Network-Particle Swarm Optimization Informed Spatial Interpolation Technique for Groundwater Quality Mapping in a Small Island Province of the Philippines. Toxics 2021, 9, 273. https://doi.org/10.3390/toxics9110273

Academic Editors: Octavio Pérez Luzardo and Katrin Vorkamp

Received: 16 September 2021

Accepted: 18 October 2021

Published: 21 October 2021

Publisher's Note: MDPI stays neutral with regard to jurisdictional claims in published maps and institutional affiliations.

Copyright: (c) 2021 by the authors. Licensee MDPI, Basel, Switzerland. This article is an open access article distributed under the terms and conditions of the Creative Commons Attribution (CC BY) license (https:/ / creativecommons.org/licenses/by/ $4.0 /)$.

\begin{abstract}
Water quality monitoring demands the use of spatial interpolation techniques due to onground challenges. The implementation of various spatial interpolation methods results in significant variations from the true spatial distribution of water quality in a specific location. The aim of this research is to improve mapping prediction capabilities of spatial interpolation algorithms by using a neural network with the particle swarm optimization (NN-PSO) technique. Hybrid interpolation approaches were evaluated and compared by cross-validation using mean absolute error (MAE) and Pearson's correlation coefficient (R). The governing interpolation techniques for the physicochemical parameters of groundwater (GW) and heavy metal concentrations were the geostatistical approaches combined with NN-PSO. The best methods for physicochemical characteristics and heavy metal concentrations were observed to have the least MAE and R values, ranging from 1.7 to 4.3 times and 1.2 to 5.6 times higher than the interpolation technique without the NN-PSO for the dry and wet season, respectively. The hybrid interpolation methods exhibit an improved performance as compared to the non-hybrid methods. The application of NN-PSO technique to spatial interpolation methods was found to be a promising approach for improving the accuracy of spatial maps for GW quality.
\end{abstract}

Keywords: groundwater; acid mine drainage; heavy metals; physicochemical characteristics; neural network; particle swarm optimization; spatial interpolation

\section{Introduction}

Acid mine drainage (AMD) is a natural or man-made environmental occurrence that transpires when sulfide minerals are exposed to weathering conditions or as a result of specific mining activities. It is a discharge with low $\mathrm{pH}$, high heavy metal, and deadly component concentrations. It is also typically formed when sulfide-abundant wastes have been introduced to the environment. This condition has been viewed as a severe environmental issue encountered by mineral extraction enterprises around the world [1,2]. AMD is caused by oxidation of pyrite and other sulfate metals when mining sources are exposed to air, microbial activity, and water. Among the potentially hazardous dissolved metals found in high quantities, iron (II) is the most prevalent and frequent in the majority of AMD locations. Iron (II) in AMD interacts with dissolved oxygen to form iron oxide precipitates often referred to as yellow boy and may kill life all along river or stream banks $[3,4]$. This problem has been identified as a significant environmental concern for 
mineral extraction companies worldwide. AMD is prevalent in both active and inactive or abandoned mining sites. However, it is less prevalent in current producing mines owing to pumping that kept the water table low. AMD is severe in closed and abandoned mines when pumps are shut off, causing water tables to recover [5]. In Asia [6,7], Europe [8], South America [9], North America [10], Africa [11], and Oceania [12], AMD studies have shown that it has detrimental consequences.

Due to the weakness and irregularity of the monitoring of AMD impacted locations, the majority of AMD originating in lower middle income to low income countries posed substantial environmental and health risks to the surrounding community. There were various locations impacted by acid mine drainage in the Philippines alone, and these incidents typically occurred in far-flung locales and remote provinces. As a result, it lacked the necessary technology and resources to monitor the amount of heavy metal (HM) content in its water resources on a regular basis. These could pose several concerns, as it was determined that good education and awareness with respect to HM in water resources are vital. A lack of understanding about this condition will result in harmful repercussions not only with respect to the environment but also to the community's inhabitants. Moreover, it was also discovered that inadequacies in environmental quality monitoring are attributable to a lack of knowledge about the dangers of HM to humans [13]. Chronic exposure to the various HM included in AMD may have serious health consequences. Chromium has been shown to have adverse effects on the liver, kidneys, circulatory system, and neurological system [14]. Exposure to cadmium has been linked to renal impairment, lung illness and cancer, bone abnormalities, kidney damage, and gastrointestinal disorders [15] Chronic exposure to elevated concentration of iron (Fe) may result in iron toxicosis which is more prevalent in children owing to their increased exposure to iron-containing products. Iron toxicosis may result in gastrointestinal bleeding, diarrhea, hypertension, lethargy, tachycardia, necrosis of the liver, and metabolic acidosis [16]. Manganese poisoning or contact with the body may harm the neurological system and central nervous system [17]. Nickel exposure has been linked to allergic contact dermatitis, respiratory cancer, and reproductive damage [18]. Lead exposure may result in damage to the liver, kidneys, and gastrointestinal tract, as well as acute or chronic neuro-logical impairment [19]. Zinc poisoning may cause harm to the neurological system, while copper toxicity can result in liver and kidney damage, as well as stomach and intestinal discomfort [20,21]. Due to these detrimental effects of HM in AMD, proper and frequent monitoring in affected sites should be implemented. This should be performed in order to ensure that enough information and warnings are provided to the surrounding community.

The most frequent form of monitoring tool is concentration maps. Spatial interpolation is the process of predicting the results of a main component at points within the same area of sample sites [22]. These maps were made with spatial data containing variety of characteristics needed for mapping and characterization to predict water quality in each location. However, spatial data are rarely available, and information on water quality is mainly obtained by spot sampling. Moreover, these techniques are tedious and require expensive instruments, tools, and/or devices. There is no clear evidence on how the performance of spatial prediction methods is affected in existing research, making it impossible to choose the best method for any dataset [23]. Several research studies investigated the performance of several geo-statistical and spatial interpolation techniques in soil moisture and drought [24], PM2.5 estimations [25], wind data [26], digital elevation model (DEM) height accuracy [27], soil organic carbon [28], and even social science [29].

The use of cutting-edge tools such as machine learning (ML) approaches coincided with the transformation of various disciplines to Industry 4.0. ML has opened up new possibilities for unraveling, measuring, and comprehending data-intensive processes in the environment. ML is a unique combination of Big Data technologies and high-performance computers. ML's overall purpose is to discover patterns in data that inform how problems that are not visible are addressed [30,31]. Numerous studies integrated a ML technique to spatial interpolation models such as Artificial Neural Network (ANN) for solar radiation 
estimation [32]; deep learning for seismic intensity [33]; ensemble ANN for atmospheric studies [34]; decision tree (DT) approach for land cover data and sodium absorption [35,36]; support vector machine (SVM) for basin precipitation [37]; long short-term memory (LSTM) neural network for PM2.5 [38]; extremely randomized trees for meteorological drought forecasting [39]; support vector regression (SVR) and correlation-based feature selection (CFS) for vehicular emissions prediction [40]; stochastic gradient boosting, cubist, random forest (RF), and model averaged neural networks for temperature maps [41]; random forest for solar radiation observation [42]; ensemble prediction approach for lake acidity prediction [43]; RF and generalized boosted regression (GBR) for soil organic carbon [44]; Non-linear AutoRegressive eXogenous (NARX) model for groundwater (GW) level prediction [45-47]; dynamic and long-term prediction of toxic HM [48,49]; and water quality prediction [50]. The use of ML integrated with spatial interpolation technique qualifies as an innovative superior substitute for traditional data application approaches due to its capability to distinguish non-linear associations among numerous constraints as opposed to other techniques that assume these connections are linear [51].

The spatial interpolation methods and its application to environmental monitoring were developed and established already, while the use of ML techniques is currently emerging and growing strongly. Several studies used ML algorithms and have recently been integrated to spatial interpolation. Du et al. investigated the suitability of various ML techniques for spatial data management. It addressed associated issues such as non-linear and high-dimensional classification and regression utilizing semi-supervised and active learning. This is to manage limited training data sizes and identify high-level features in the dataset. The findings of the research of Du et al. indicated that ML techniques are appropriate for overcoming these difficulties in spatial data processing that enhance the performance of classification and prediction skills of the model [52]. Moreover, the SVR and RF were the most widely explored ML technique in reference to its integration to spatial interpolation [53].

According to Stahl et al., the sample density influences the performance of the spatial interpolation technique. When the sample density is low, the performance of spatial interpolation technique is deficient. However, when sample density is high, the performance of spatial interpolation technique improves [54]. Spatial data are rarely available, and the majority of information on GW quality is gathered via spot sampling. Hence, the spatial interpolation technique is useful in GW quality monitoring and mapping. Therefore, this research addresses the issue in sampling density and the challenge of spot sampling access by highlighting the application of a hybrid neural network with particle swarm optimization (NN-PSO) with the spatial interpolation technique for GW quality mapping.

\section{Materials and Methods}

The study uses NN-PSO methodology relative to a range of interpolation types, including deterministic techniques, geostatistical methods, and interpolation with barriers, to improve its GW quality prediction performance. The subsequent sections detail the study's focus and the combined strategies used to create enhanced spatial maps.

\subsection{The Area of Study}

The Province of Marinduque, the smallest island province in the MIMAROPA Region (or Region IV-B), is the area of research. Marinduque Island, about $200 \mathrm{~km}$ south of Manila, is a province known as Philippines' heart due to its geometric shape and geographical location [55]. With a total land area of 96,000 hectares, Marinduque is a 4th income class island province made up of six municipalities: Boac, Buenavista, Mogpog, Gasan, Santa Cruz, and Torrijos. The province's topography is mostly mountainous, with continuous and severe slope areas. Considering the province's overall land area, 77 percent, or 737.2 square kilometers, is classified as alienable land, while the remaining 23 percent, or 222.05 square kilometers, is classified as forest land [56]. The island province has a Climate Type III climate, with the dry season lasting from November to April and the wet season covering 
the rest of the year [57]. The annual rainfall in the province of Marinduque range from 1700 to $2500 \mathrm{~mm}$ [58].

Several bodies of water, primarily rivers and their tributaries, make up the province of Marinduque. The province's major rivers and tributaries have a total length of $178 \mathrm{~km}$ which is composed of the municipalities of Boac (20.11 percent), Buenavista (10.96 percent), Gasan (19.49 percent), Mogpog (20.06 percent), Santa Cruz (15.22 percent), and Torrijos (15.22 percent) (14.16 percent). The province has a total of $614.1003 \mathrm{~km}^{2}$ considering the drainage area. The Municipality of Boac has 34.80 percent of the total surface water body drainage area, followed by 7.47 percent in the Municipality of Buenavista, 11.30 percent in the Municipality of Gasan, 14.61 percent in the Municipality of Mogpog, 19.58 percent in the Municipality of Santa Cruz, and 12.24 percent in Torrijos [59].

Figure 1 depicts 34 watersheds that make up the province of Marinduque. With an extent of $195.94 \mathrm{~km}^{2}$, the Boac Watershed is the province's largest watershed. The list of watersheds of the province of Marinduque is shown in Table 1.

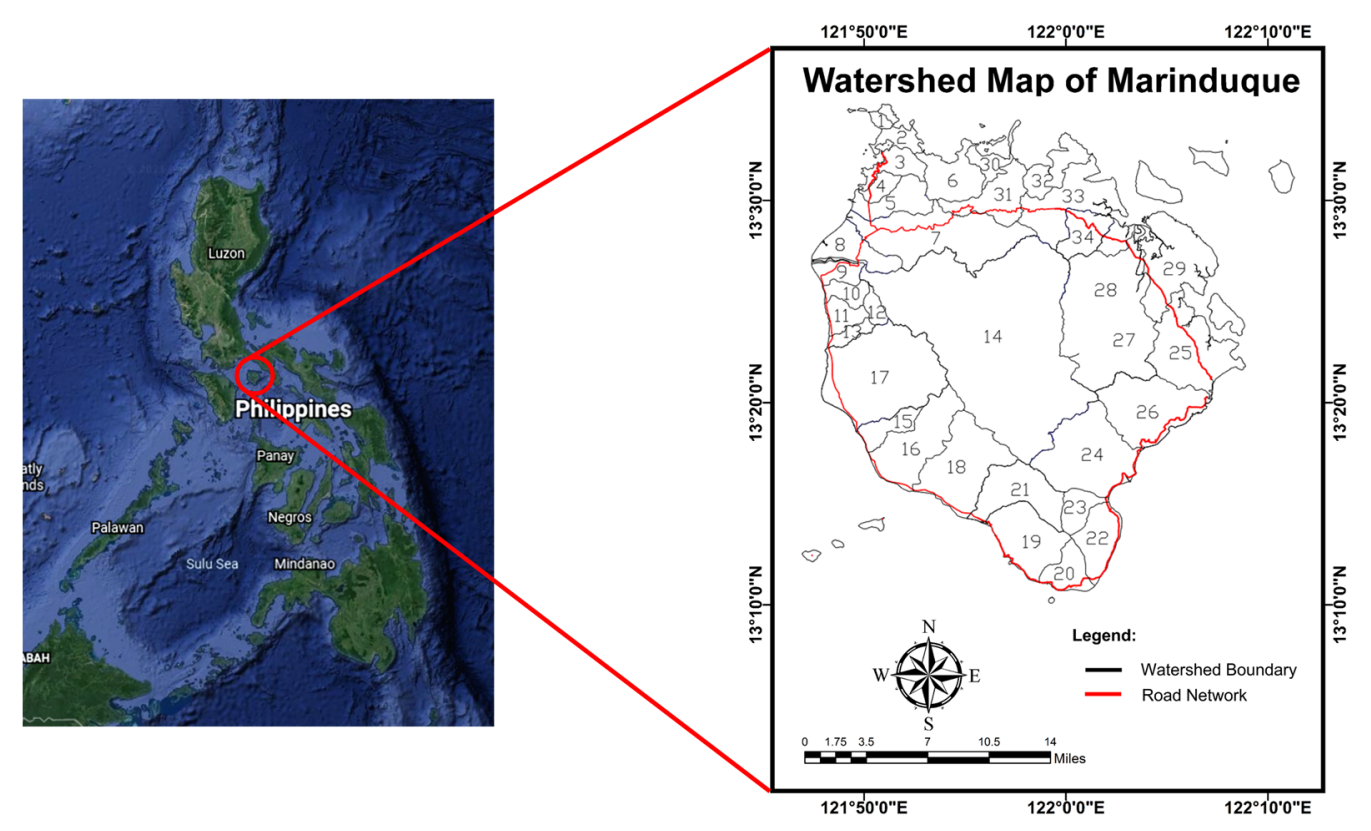

Figure 1. Watershed Map of Marinduque.

Marinduque Island is home to one of the Philippines' largest copper deposits. Since 1969, copper mining activities have been carried out on the island. Mine tailings from these activities began to be deposited in Calancan Bay in 1975. Since then and until 1997, around 200 million tons have been dumped [60].

In the 1990s, the island was hit by two mining catastrophes. The first incident occurred in 1993, when the Maguilaguila siltation dam in San Antonio, Sta. Cruz, collapsed. This caused property and agricultural damage and adverse effects to public health in downstream communities [61]. Three years later, in 1996, the Tapian Pit collapsed, releasing between 180,000 and 260,000 cubic meters of mine tailings into the Boac River, causing environmental and community damages [62]. 
Table 1. List of Watershed in Marinduque Province.

\begin{tabular}{clcl}
\hline Watershed No. & \multicolumn{1}{c}{ Name of Watershed } & Watershed No. & \multicolumn{1}{c}{ Name of Watershed } \\
\hline 1 & Hinanggayon-Mogpog & 18 & Catangon-Buenavista \\
2 & Guisan-Mogpog & 19 & Libas-Buenavista \\
3 & Balanacan-Mogpog & 20 & Lipata-Buenavista \\
4 & Capayang-Mogpog & 21 & Buenavista \\
5 & Laon-Mogpog & 22 & Dampulan-Torrijos \\
6 & Sayao-Mogpog & 23 & Marlanga-Torrijos \\
7 & Mogpog & 24 & Cabuyo-Torrijos \\
8 & Pili-Boac & 25 & Matuyatuya-Torrijos \\
9 & Murallon-Boac & 26 & Torrijos \\
10 & Ihatub-Boac & 27 & Tambangan-Santa Cruz \\
11 & Caganhao-Boac & 28 & Tawiran-Tagum \\
12 & Maybo-Boac & 29 & Tagum-Santa Cruz \\
13 & Bunganay-Boac & 30 & Botilao-Santa Cruz \\
14 & Boac & 31 & Dolores-Santa Cruz \\
15 & Banot-Gasan & 32 & Kamandugan-Santa Cruz \\
16 & Dawis-Gasan & 33 & Hupi-Santa Cruz \\
17 & Gasan & 34 & Santa Cruz \\
\hline
\end{tabular}

\subsection{Sampling, Storage, and Collection of GW Samples}

GW samples were gathered from different wells in six municipalities in Marinduque and stored in plastic bottles $(1 \mathrm{~L})$. Data were collected and stored in compliance with EPA No. SESDPROC-301-R3, which is the GW sampling operational procedure [63]. The Hanna HI 9811-5 handheld multi-parameter sampler was used to collect all field measurements, including in situ physicochemical parameters for GW samples, such as temperature (in Celsius), $\mathrm{pH}$, total dissolved solids (TDS) in milligrams per liter, and electrical conductivity (EC) in microsiemens per centimeter. Two separate geographical maps were created to depict dry and wet seasons in a year [64]. The map and details of the sampling locations are presented in Figure 2 and Table 2.

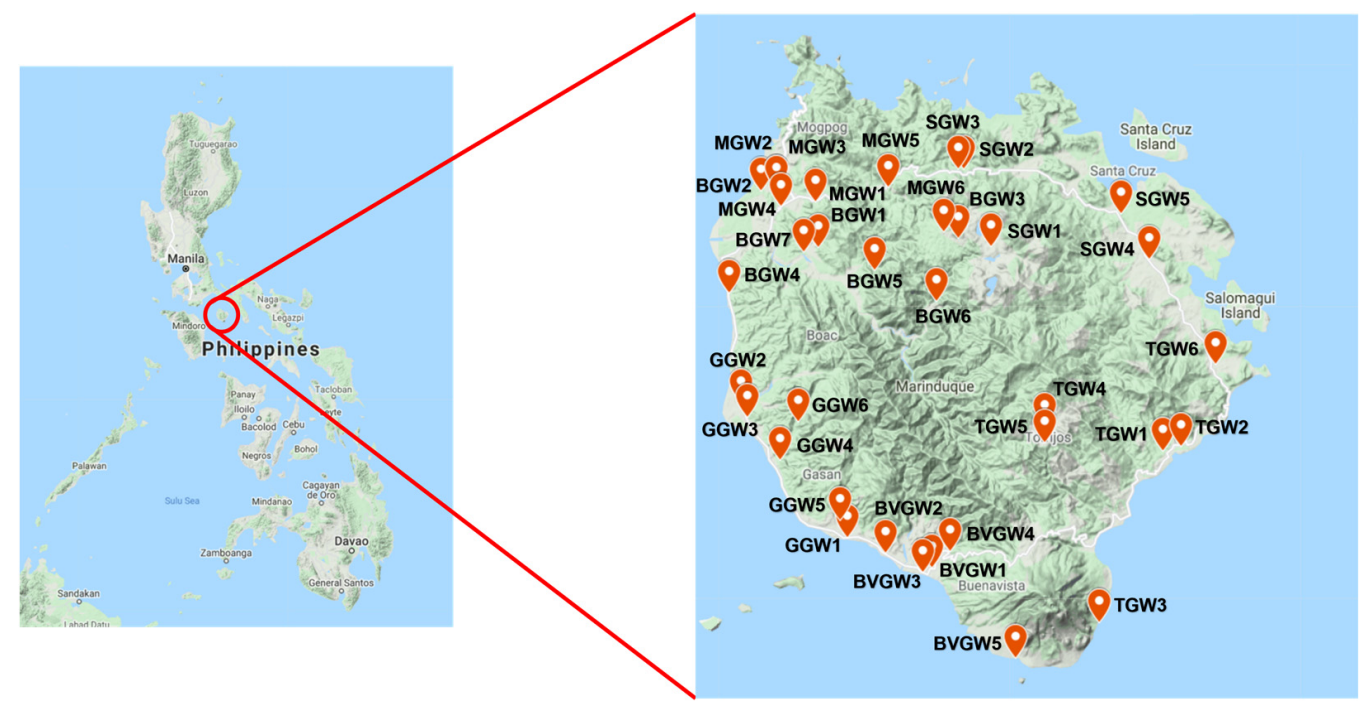

Figure 2. Map of the Sampling Locations. 
Table 2. Coordinates of the Sampling Locations.

\begin{tabular}{|c|c|c|c|c|c|}
\hline $\begin{array}{c}\text { Sampling } \\
\text { Location Code }\end{array}$ & Barangay & Municipality & Latitude & Longitude & Elevation \\
\hline BGW1 & Tagwak & Boac & $13.44552^{\circ} \mathrm{N}$ & $121.87620^{\circ} \mathrm{E}$ & $96 \mathrm{~m}$ \\
\hline BGW2 & Maligaya & Boac & $13.47936^{\circ} \mathrm{N}$ & $121.84087^{\circ} \mathrm{E}$ & $10 \mathrm{~m}$ \\
\hline BGW3 & Puting Buhangin & Boac & $13.45117^{\circ} \mathrm{N}$ & $121.96087^{\circ} \mathrm{E}$ & $282 \mathrm{~m}$ \\
\hline BGW4 & Balarin & Boac & $13.41933^{\circ} \mathrm{N}$ & $121.82200^{\circ} \mathrm{E}$ & $17 \mathrm{~m}$ \\
\hline BGW5 & Bantay & Boac & $13.43247^{\circ} \mathrm{N}$ & $121.90953^{\circ} \mathrm{E}$ & $208 \mathrm{~m}$ \\
\hline BGW6 & Hinapulan & Boac & $13.41442^{\circ} \mathrm{N}$ & $121.94785^{\circ} \mathrm{E}$ & $242 \mathrm{~m}$ \\
\hline BGW7 & Boton & Boac & $13.44292^{\circ} \mathrm{N}$ & $121.86732^{\circ} \mathrm{E}$ & $61 \mathrm{~m}$ \\
\hline MGW1 & Sumangga & Mogpog & $13.47268^{\circ} \mathrm{N}$ & $121.87412^{\circ} \mathrm{E}$ & $68 \mathrm{~m}$ \\
\hline MGW2 & $\begin{array}{l}\text { Nangka Dos } \\
\quad \text { (Site 1) }\end{array}$ & Mogpog & $13.47972^{\circ} \mathrm{N}$ & $121.85047^{\circ} \mathrm{E}$ & $24 \mathrm{~m}$ \\
\hline MGW3 & $\begin{array}{l}\text { Nangka Dos } \\
\quad \text { (Site 2) }\end{array}$ & Mogpog & $13.47973^{\circ} \mathrm{N}$ & $121.85053^{\circ} \mathrm{E}$ & $24 \mathrm{~m}$ \\
\hline MGW4 & Janagdong & Mogpog & $13.46952^{\circ} \mathrm{N}$ & $121.85326^{\circ} \mathrm{E}$ & $29 \mathrm{~m}$ \\
\hline MGW5 & Butansapa & Mogpog & $13.48100^{\circ} \mathrm{N}$ & $121.91803^{\circ} \mathrm{E}$ & $145 \mathrm{~m}$ \\
\hline MGW6 & Putting Buhangin & Mogpog & $13.45533^{\circ} \mathrm{N}$ & $121.95198^{\circ} \mathrm{E}$ & $265 \mathrm{~m}$ \\
\hline BVGW1 & Malbog (Site 1) & Buenavista & $13.25813^{\circ} \mathrm{N}$ & $121.94488^{\circ} \mathrm{E}$ & $77 \mathrm{~m}$ \\
\hline BVGW2 & Malbog (Site 2) & Buenavista & $13.26675^{\circ} \mathrm{N}$ & $121.91648^{\circ} \mathrm{E}$ & $103 \mathrm{~m}$ \\
\hline BVGW3 & Libas (Site 1) & Buenavista & $13.25553^{\circ} \mathrm{N}$ & $121.93958^{\circ} \mathrm{E}$ & $69 \mathrm{~m}$ \\
\hline BVGW4 & Libas (Site 2) & Buenavista & $13.26807^{\circ} \mathrm{N}$ & $121.95612^{\circ} \mathrm{E}$ & $70 \mathrm{~m}$ \\
\hline BVGW5 & Bagtingon & Buenavista & $13.20521^{\circ} \mathrm{N}$ & $121.99482^{\circ} \mathrm{E}$ & $85 \mathrm{~m}$ \\
\hline BVGW6 & Sihi & Buenavista & $13.25813^{\circ} \mathrm{N}$ & $121.94488^{\circ} \mathrm{E}$ & $371 \mathrm{~m}$ \\
\hline GGW1 & Banuyo & Gasan & $13.27573^{\circ} \mathrm{N}$ & $121.89303^{\circ} \mathrm{E}$ & $5 \mathrm{~m}$ \\
\hline GGW2 & Masiga & Gasan & $13.35505^{\circ} \mathrm{N}$ & $121.82912^{\circ} \mathrm{E}$ & $16 \mathrm{~m}$ \\
\hline GGW3 & Libtangin & Gasan & $13.34647^{\circ} \mathrm{N}$ & $121.83297^{\circ} \mathrm{E}$ & $21 \mathrm{~m}$ \\
\hline GGW4 & Matandang Gasan & Gasan & $13.32178^{\circ} \mathrm{N}$ & $121.85268^{\circ} \mathrm{E}$ & $46 \mathrm{~m}$ \\
\hline GGW5 & Dawis & Gasan & $13.28638^{\circ} \mathrm{N}$ & $121.88908^{\circ} \mathrm{E}$ & $42 \mathrm{~m}$ \\
\hline GGW6 & Tiguion & Gasan & $13.34365^{\circ} \mathrm{N}$ & $121.86365^{\circ} \mathrm{E}$ & $86 \mathrm{~m}$ \\
\hline TGW1 & Marlangga & Torrijos & $13.32683^{\circ} \mathrm{N}$ & $122.08442^{\circ} \mathrm{E}$ & $56 \mathrm{~m}$ \\
\hline TGW2 & Poctoy (Site 1) & Torrijos & $13.32943^{\circ} \mathrm{N}$ & $122.09528^{\circ} \mathrm{E}$ & $37 \mathrm{~m}$ \\
\hline TGW3 & Dampulan & Torrijos & $13.22590^{\circ} \mathrm{N}$ & $122.04562^{\circ} \mathrm{E}$ & $25 \mathrm{~m}$ \\
\hline TGW4 & Sibuyao & Torrijos & $13.34091^{\circ} \mathrm{N}$ & $122.01261^{\circ} \mathrm{E}$ & $444 \mathrm{~m}$ \\
\hline TGW5 & Poctoy (Site 2) & Torrijos & $13.33164^{\circ} \mathrm{N}$ & $122.01261^{\circ} \mathrm{E}$ & $34 \mathrm{~m}$ \\
\hline TGW6 & Matuyatuya & Torrijos & $13.37778^{\circ} \mathrm{N}$ & $122.11611^{\circ} \mathrm{E}$ & $15 \mathrm{~m}$ \\
\hline SGW1 & San Antonio & $\begin{array}{l}\text { Santa } \\
\text { Cruz }\end{array}$ & $13.44612^{\circ} \mathrm{N}$ & $121.98055^{\circ} \mathrm{E}$ & $272 \mathrm{~m}$ \\
\hline SGW2 & Dolores (Site 1) & $\begin{array}{l}\text { Santa } \\
\text { Cruz }\end{array}$ & $13.49177^{\circ} \mathrm{N}$ & $121.96383^{\circ} \mathrm{E}$ & $185 \mathrm{~m}$ \\
\hline SGW3 & Dolores (Site 2) & $\begin{array}{l}\text { Santa } \\
\text { Cruz }\end{array}$ & $13.49183^{\circ} \mathrm{N}$ & $121.96087^{\circ} \mathrm{E}$ & $191 \mathrm{~m}$ \\
\hline SGW4 & Napo & $\begin{array}{l}\text { Santa } \\
\text { Cruz }\end{array}$ & $13.43878^{\circ} \mathrm{N}$ & $122.07607^{\circ} \mathrm{E}$ & $65 \mathrm{~m}$ \\
\hline SGW5 & Matalaba & $\begin{array}{l}\text { Santa } \\
\text { Cruz }\end{array}$ & $13.46595^{\circ} \mathrm{N}$ & $122.05897^{\circ} \mathrm{E}$ & $53 \mathrm{~m}$ \\
\hline
\end{tabular}

\subsection{Elemental Analysis of Groundwater Samples}

The measurement of total metals, which includes suspended and dissolved components as well as soluble metals, is required when looking for HMs in GW samples. The EPA Method 3005A was employed for Inductively Coupled Plasma spectroscopy using water acid digestion for total dissolved and recoverable metals as the reference guidelines for GW sample digestion $[65,66]$.

\subsection{Descriptive and Multivariate Statistical Analysis}

The IBM Statistical Package for the Social Sciences (SPSS) was utilized to evaluate descriptive statistics linked to GW physicochemical parameters and HM intensities. Skewness and kurtosis were applied to assess the asymmetry of physicochemical characteristics and HM concentrations in GW. The skewness of the GW quality parameters shows the 
relative locations of the median and mean, whereas the kurtosis represents the form of the distribution $[67,68]$. The most important element in characterizing the variability of GW physicochemical parameters and HM content was the coefficient of variation (CV). The coefficient of variability was used to analyze the dataset's variability as follows: $\mathrm{CV}$ $\leq 15 \%$, low; $15 \%<\mathrm{CV} \leq 35 \%$, intermediate; and $\mathrm{CV} \geq 35 \%$, high [69]. Moreover, a Kolmogorov-Smirnov (K-S) test was employed to test the normality of the datasets and to examine if the GW quality parameters have a normal distribution [70].

The GW quality data are frequently identified and evaluated using multivariate statistical analysis. Multivariate statistical approaches enable the extraction of meaningful meaning from data by simplifying, organizing, and classifying it [71]. Using a correlation matrix utilizing MATLAB 2021a and R studio, the relationship between physicochemical parameters and HM intensities in GW in the research area was observed. The correlation matrix established occurrence, HM associations, and potential source of contaminants in the area of study [72]. The $R$ value of -1 signifies that the parameter shifts inversely with respect to the other. A very strong correlation is exhibited by $0.90<\mathrm{r}<1.00$, strong correlation by $0.70<\mathrm{r}<0.89$, moderate correlation by $0.40<\mathrm{r}<0.69$, weak correlation by $0.10<\mathrm{r}<0.39$, and negligible correlation by $0<\mathrm{r}<0.10$. There is no association between the two variables if the correlation is zero [73].

\subsection{Machine Learning: Hybrid Neuro-Particle Swarm Optimization Modelling}

Machine learning is an application of artificial intelligence that allows software applications and uses statistical models and algorithms to analyze and draw interferences from patterns in data. This study uses MATLAB 2021a to enhance the prediction capability of the spatial interpolation maps of GW quality using a Particle Swarm Optimization (PSO) trained Artificial Neural Network model. Subsequent sections below elaborate how machine learning was used as technique in creating GW quality mapping. Hence, pages 7-9 discuss and illustrate how machine learning has been used in the study and which stage of the technique development been used.

\subsubsection{Backpropagation Neural Network (BP-NN)}

The ANN is an approach inspired by a real biological neuron that has been used in prediction and forecasting, particularly for complicated and non-linear systems such as environmental problems such as water quality modeling [74]. The Artificial Neural Network learns by training the connectivity between the neurons, which is performed using known input and output values provided in an organized manner so that the network can extract the relationship and patterns in the dataset [75]. MATLAB R2021a was used to create the neural network model, which included 70 percent, 15 percent, and 15 percent data partitioning for the data sets utilized in the training, validation, and testing stage, respectively [76]. The Levenberg-Marquardt algorithm was employed as the model's training algorithm since it is the quickest method to train a moderate-sized feed forward neural network with several hundred weights [77]. The model uses a hyperbolic tangent sigmoid (tansig) transfer function as the driving component for the interaction between a neuron's weights $(\mathrm{W})$ and the input element. It also has a significant impact on the network's complexity and performance, and it was chosen because it provides ideal decision biases (b). The tansig transfer function can understand the complex non-linear connection between the input and output parameters by producing values ranging from -1 to +1 [78]. Figure 3 depicts the design and architecture of the ANN model development. 


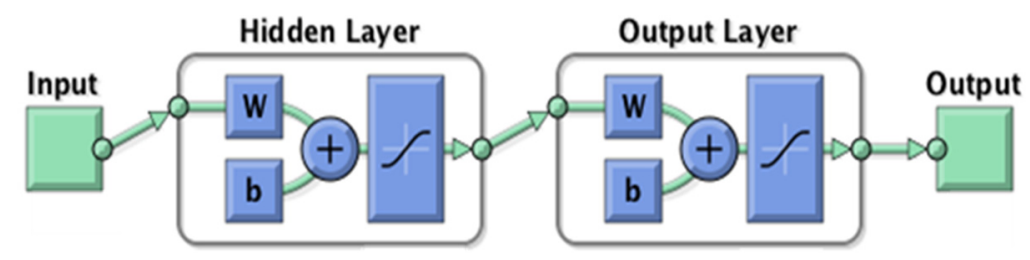

Figure 3. Architecture of the ANN showing the weights and biases.

\subsubsection{Particle Swarm Optimization (PSO)}

One of the most frequently used ANN models is the BP-NN, which is a multiple layer feed-forward ANN trained using the error BP method. BP-NN, on the other hand, has weaknesses, which may be fixed by combining it with the Particle Swarm Optimization (PSO) approach, which improves the model's accuracy and efficiency [79]. The PSO approach is utilized in this research in order to optimize the link weights of the ANN.

The PSO is a type of swarm intelligence approach used in evolutionary computing. These techniques were influenced by natural bio-social phenomena such as flocks of birds, schools of fish, and other natural bio-social phenomena. The PSO is particularly applicable for non-linear generalization capabilities with discontinuities because of its quick convergence and robustness. PSO is a promising choice for optimization modelling when compared to other evolutionary algorithms [80,81]. Due to its faster learning speed and lower memory demand, the PSO is preferred over other optimization algorithms including the Genetic Algorithm (GA) and Imperialist Competition Algorithm (ICA) [82].

\subsubsection{Hybrid NN-PSO Model}

The Neural Network (NN) model's connection weights are optimized via Particle Swarm Optimization (PSO). The PSO is utilized because it can determine the best solution while also reducing the ANN's errors. The PSO calculates the positions of the particles and transmits it to the learning process. The optimal weights and biases for the training method of the ANN were found using the PSO-generated particle population [83]. The framework of the application of the NN-PSO method in spatial interpolation techniques is presented in Figure 4.

\subsubsection{Performance Evaluation}

The correlation coefficient (R) and mean squared error (MSE) were utilized to assess the performance of the NN-PSO model. A complete positive correlation is implied by a $R$ value of 1 . The $R$ value indicates how closely two variables were linked [84]. The $R$ values were observed and utilized as performance indicators throughout the validation and testing phases. The $\mathrm{R}$ value was utilized in the validation phase to assess network generalization, terminate the simulation when generalization ceased to improve, and determine the optimum architecture, while the $\mathrm{R}$ value in the testing phase serves as an additional independent measure of network performance during and after the simulation $[85,86]$. In a simulation using the NN-PSO method, the MSE was minimized which includes the overall MSE in the validation and testing phases. The MSE is a helpful tool for assessing model predictions since it reflects the sum of squared bias and variance. For the model, zero is the optimum value for the MSE [87]. The equations for the R and MSE are shown in Equations (1) and (2) where " $N$ " is the number of data sets, $y_{0}$ is the predicted value, $y_{m}$ is the measured value, $\overline{\bar{y}}$ and $y_{m}$ were the mean values, and $e_{i}$ is the contrast between the measured values and the predicted values [88]. 


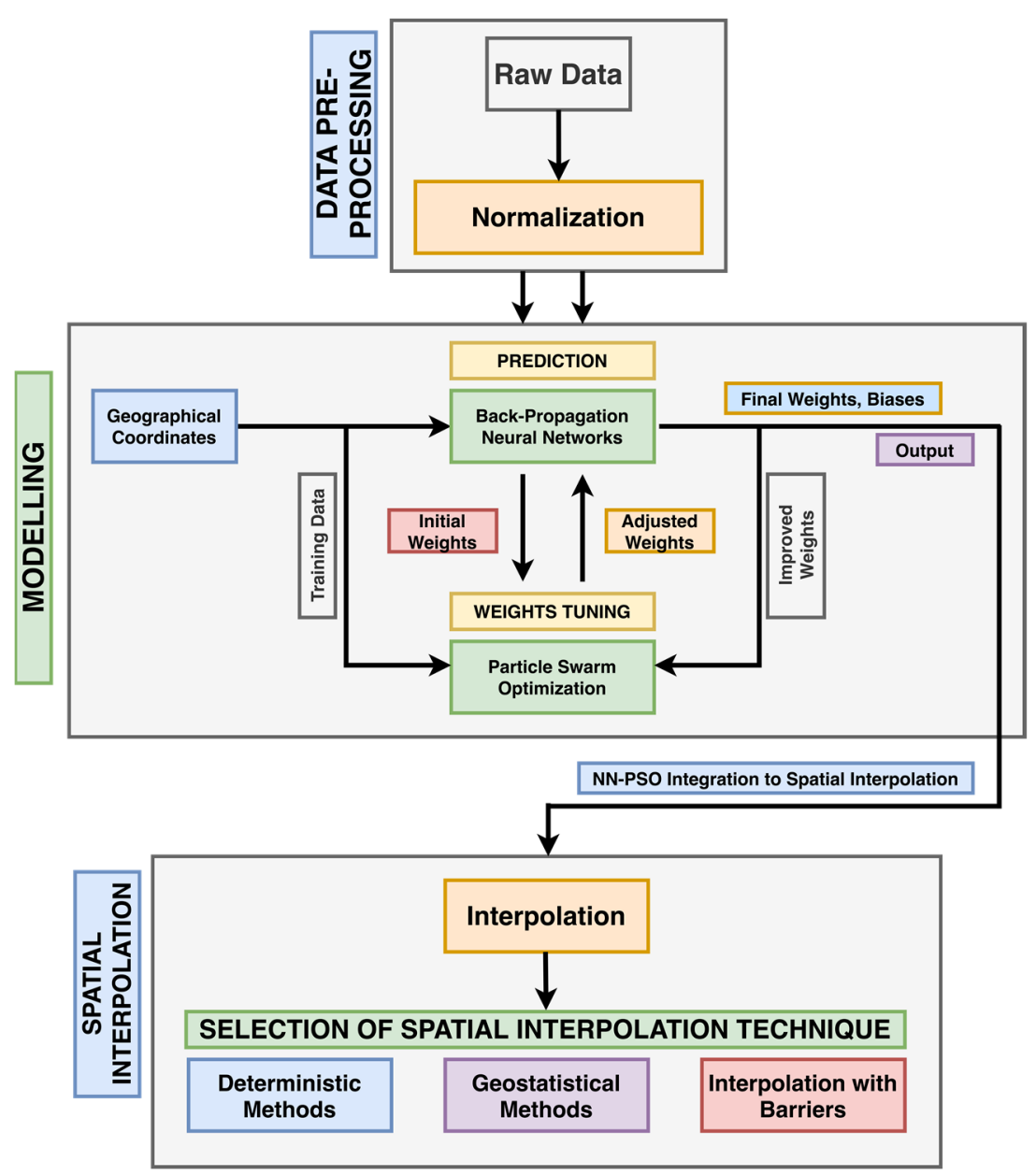

Figure 4. Schematic diagram of the NN-PSO informed spatial interpolation.

$$
\begin{gathered}
r=\frac{\sum_{i=1}^{N}\left(y_{0}-\bar{y}\right)\left(y_{m}-\overline{y_{m}}\right)}{\sqrt{\sum_{i=1}^{N}\left(y_{0}-\bar{y}\right)^{2} \sum_{i-1}^{N}\left(y_{m}-\overline{y_{m}}\right)^{2}}} \\
M S E=\frac{1}{n} \sum_{i=1}^{N}\left(e_{i}\right)^{2}
\end{gathered}
$$

\subsection{Spatial Interpolation Methods for Heavy Metals}

The measured physicochemical parameter and detected HM concentrations were mapped by utilizing the ArcGIS platform. The sampling sites' precise locations were recorded using a GARMIN Montana 650 GPS, which was integrated onto the Geographical Information System (GIS) platform. Moreover, data collected from the GW samples were applied to create maps operating the Geostatistical Analyst Tool and Geostatistical Wizard in the ArcGIS software. The different interpolation methods are utilized to apply spatial analysis which are included in the ArcGIS spatial analysis extension tool. Deterministic techniques, geostatistical methods, and interpolation with barriers are among the three (3) interpolation types utilized in the study.

The deterministic techniques include Inverse Distance Weighting (IDW), Global Polynomial Interpolation (GPI), Radial Basis Functions (RBF), and Local Polynomial Interpolation (LPI). The IDW is a deterministic spatial interpolation approach that determines the data in an unsampled location by using the data from a distributed collection of sampled 
locations. The data in an unidentified site are based on the weighted sum of the values of the recognized locations which is based on the distance of the unidentified site to the sampled locations [89]. GPI is a deterministic and approximate trend surface analysis wherein a smooth two-dimensional polynomial function of first, second, or higher degree is used to describe a surface. It computes the target point's value by using all nearby points [90]. RBF achieves its accuracy by using a large number of accurate interpolators that reduce the overall curvature of the surface depending on the space between the interpolated and sampled locations [91]. The LPI method includes fitting the weighted least squares to store the data inside the search ellipse of the grid node wherein the projected value is used to calculate the surface value of the neighboring points that can be used to build surface that account for short-range variation [92].

The geostatistical techniques include Ordinary Kriging (OK), Universal Kriging (UK), and Empirical Bayesian Kriging (EBK). OK is a linear geostatistical process that depends less on stationary mean assumptions by using the search radius. The OK method approximates values in unsampled regions by averaging nearby data and visualizing the correlations between surrounding values as a function of the geographic distance between the sites in the area of study using a weighted average of neighboring data and a variogram [93]. UK uses a trend surface that may include factors that account for variation in the global component, and it more likely to provide residuals that are more closely related to a stationary mean with identical distribution [94]. EBK automates the most time-consuming and challenging stages in creating a realistic kriging model. EBK automatically optimizes by subsetting and simulating several semi-variogram models instead of a single semivariogram. EBK creates a semi-variogram model from existing data and then simulates the new value at each input data point until the final calculation of the new semi-variogram model based on the simulated data [95].

The interpolation with barriers includes Kernel Smoothing (KS) and Diffusion Kernel (DK). The DK employs a complex distance metric specified by the cost surface, which is a widely used raster function that estimates the cost of traveling from one cell of a raster to the next, and then generates forecasts on automatically chosen grids. The KS method is a variation of first order LPI that avoids computing uncertainty by using a technique similar to that used to estimate regression coefficients in ridge regressions. KS utilizes the shortest distance between locations to connect places on opposing sides of an absolute barrier using a sequence of straight lines [96]. These interpolation techniques were implemented to the data arrays in order to distinguish the concentration map that best describes the HM pollution in the province of Marinduque [97].

\subsection{Cross Validation}

A frequently utilized technique for comparing the interpolation methods is cross validation. Due to the small sample size, cross validation was used. A cross validation procedure consists in removing data points one at a time, interpolating a value from the remaining observations, and comparing that value to the real value [98].

The Mean Absolute Error (MAE) and Pearson's Correlation Coefficient (R) were used to determine the predictive accuracy of distinct methods, with the least MAE representing the most exact predictions. Equation (3) shown below is used to calculate MAE:

$$
M A E=\frac{1}{n} \sum_{i=1}^{n}\left|Z_{i}-Z\right|
$$

where $Z_{i}$ is the predicted value, $Z$ is the observed value, and $n$ is the number of observations [99].

\section{Results}

The major findings of the study are presented in this section. This section contains all the maps created with the integrated NN-PSO and spatial interpolation algorithms. This part also includes the data's descriptive statistics as well as the maps' prediction performance. 


\subsection{Heavy Metals in Groundwater}

Table 3 shows descriptive data for GW physicochemical characteristics and HM concentrations.

Table 3. Descriptive statistics for dry season physicochemical properties and HM concentrations in GW in the study area.

\begin{tabular}{ccccccc}
\hline Parameter & Mean & $\begin{array}{c}\text { PNSDW 2017 } \\
\text { Guideline } \\
\text { Value }\end{array}$ & $\begin{array}{c}\text { WHO } \\
\text { Guideline } \\
\text { Value }\end{array}$ & Skewness Kurtosis & CV\% \\
\hline Temp $\left({ }^{\circ} \mathrm{C}\right)$ & 36.80 & - & - & 0.417 & -1.513 & 24.20 \\
$\mathrm{pH}$ & 7.02 & $6.5-8.5$ & $6.5-9.2$ & -0.089 & -1.678 & 10.30 \\
$\mathrm{EC}(\mu \mathrm{s} / \mathrm{cm})$ & 935.17 & - & 1500 & 0.625 & -1.166 & 88.40 \\
$\mathrm{TDS}(\mathrm{mg} / \mathrm{L})$ & 372.77 & 600 & 1200 & 1.189 & 2.579 & 43.10 \\
$\mathrm{Cr}(\mathrm{ppm})$ & 0.06285 & 0.050 & 0.050 & 0.693 & 0.232 & 47.40 \\
$\mathrm{Cd}(\mathrm{ppm})$ & 0.03283 & 0.003 & 0.003 & 0.800 & -1.300 & 140.16 \\
$\mathrm{Fe}(\mathrm{ppm})$ & 2.92944 & 1.000 & 0.300 & 4.026 & 14.917 & 378.74 \\
$\mathrm{Mn}(\mathrm{ppm})$ & 0.71753 & 0.400 & 0.400 & 3.165 & 9.205 & 264.87 \\
$\mathrm{Ni}(\mathrm{ppm})$ & 0.03902 & 0.070 & 0.070 & 0.754 & -1.170 & 124.54 \\
$\mathrm{~Pb}(\mathrm{ppm})$ & 0.05572 & 0.010 & 0.010 & 0.226 & -1.779 & 94.68 \\
$\mathrm{Zn}(\mathrm{ppm})$ & 4.32901 & 5.000 & 3.000 & 3.374 & 10.135 & 299.87 \\
$\mathrm{Cu}(\mathrm{ppm})$ & 0.12688 & 1.000 & 2.000 & 0.212 & -1.530 & 77.03 \\
\hline
\end{tabular}

During the dry season, all GW physicochemical parameters and HM concentrations were observed to be highly variable, except for $\mathrm{pH}$ and temperature, which were found to be low and moderately variable, respectively. The Kolmogorov-Smirnov test revealed that the dry season physicochemical characteristics and HM concentrations of GW in the research region were not uniformly distributed, with all parameters having $p<0.05$.

The GW physicochemical characteristics were compared to Philippine National Standards for Drinking Water (PNSDW) 2017 and World Health Organization (WHO) Drinking Water Standards. Table 3 shows that the $\mathrm{pH}$ of the GW during the dry season ranged from 6.10 to 7.90, with an average pH of 7.02, which is within the PNSDW 2017 and WHO standards. The EC of the GW during the dry season varies from 80 to $2350 \mu \mathrm{S} / \mathrm{cm}$ with mean EC of $935.17 \mu \mathrm{S} / \mathrm{cm}$, which is below the maximum value set by the WHO. The asymmetries of the physicochemical characteristics and HM concentration of the GW during the dry season were measured by skewness and kurtosis. With the exception of $\mathrm{pH}$, all physicochemical characteristics and HM concentrations in GW exhibit a positive skewness, meaning that the right side is longer than the left. This indicates that an asymmetry distribution with a positive skewness tends to be less concentrated. TDS, Cr, Fe, Mn, and $\mathrm{Zn}$ are the only elements with positive kurtosis values, indicating a steeper distribution than normal.

A comparative assessment of HM concentrations of GW during the dry season was likewise performed relative to the PNSDW 2017 and WHO Standards for Drinking Water. Mean concentrations of $\mathrm{Ni}$ ranging from 0.000110 to $0.125310 \mathrm{ppm}$ and $\mathrm{Cu}$ ranging from 0.000868 to 0.260497 ppm were below the limit of PNSDW 2017 and WHO standards for drinking water. Zn concentration ranged between 0.000985 and $56.96133 \mathrm{ppm}$, with mean concentration exceeding the WHO limit. Average concentrations of $\mathrm{Cr}, \mathrm{Cd}, \mathrm{Fe}$, and $\mathrm{Pb}$ exceeded the allowable limits by PNSDW 2017 and WHO Standards. Moreover, some locations had concentrations way above the limit.

During the wet season, all GW physicochemical parameters except for $\mathrm{pH}$ and temperature and HM concentrations showed considerable variability. The Kolmogorov-Smirnov test revealed that the wet season physicochemical characteristics and HM concentrations of GW in the research region were not normally distributed, with $p<0.05$ for all parameters.

Wet season GW physicochemical characteristics were also compared to PNSDW 2017 and WHO Drinking Water Standards. Table 4 indicates that the $\mathrm{pH}$ of the GW throughout 
the wet season ranged from 6.00 to 9.55 , with a mean $\mathrm{pH}$ of 7.43 , which is within the PNSDW 2017 and WHO standards.

Table 4. Descriptive statistics for wet season physicochemical properties and HM concentrations in GW in the study area.

\begin{tabular}{ccccccc}
\hline Parameter & Mean & $\begin{array}{c}\text { PNSDW 2017 } \\
\text { Guideline } \\
\text { Value }\end{array}$ & $\begin{array}{c}\text { WHO } \\
\text { Guideline } \\
\text { Value }\end{array}$ & Skewness Kurtosis & CV\% \\
\hline Temp $\left({ }^{\circ} \mathrm{C}\right)$ & 31.55 & - & - & 0.800 & -0.718 & 18.25 \\
$\mathrm{pH}$ & 7.43 & $6.5-8.5$ & $6.5-9.2$ & 0.474 & -1.104 & 15.62 \\
$\mathrm{EC}(\mu \mathrm{S} / \mathrm{cm})$ & 780.61 & - & 1500 & 1.082 & -0.183 & 107.93 \\
$\mathrm{TDS}(\mathrm{mg} / \mathrm{L})$ & 428.09 & 600 & 1200 & 0.978 & -0.608 & 109.80 \\
$\mathrm{Cr}(\mathrm{ppm})$ & 0.08929 & 0.050 & 0.050 & -0.048 & -1.787 & 81.20 \\
$\mathrm{Cd}(\mathrm{ppm})$ & 0.06860 & 0.003 & 0.003 & -0.695 & -1.377 & 65.30 \\
$\mathrm{Fe}(\mathrm{ppm})$ & 16.0672 & 1.000 & 0.300 & 0.899 & -1.095 & 143.96 \\
$\mathrm{Mn}(\mathrm{ppm})$ & 3.99553 & 0.400 & 0.400 & 0.186 & -1.860 & 99.20 \\
$\mathrm{Ni}(\mathrm{ppm})$ & 0.05355 & 0.070 & 0.070 & 0.276 & -1.749 & 100.63 \\
$\mathrm{~Pb}(\mathrm{ppm})$ & 0.06298 & 0.010 & 0.010 & -0.086 & -1.904 & 89.07 \\
$\mathrm{Zn}(\mathrm{ppm})$ & 23.7530 & 5.000 & 3.000 & 0.358 & -1.629 & 100.99 \\
$\mathrm{Cu}(\mathrm{ppm})$ & 0.13846 & 1.000 & 2.000 & -0.103 & -1.786 & 80.75 \\
\hline
\end{tabular}

The EC of the GW during the wet season varies from 70 to $2640 \mu \mathrm{S} / \mathrm{cm}$ with average $780.61 \mu \mathrm{S} / \mathrm{cm}$ which is inside the acceptable value set by the WHO. The asymmetries of the physicochemical characteristics and HM concentration in GW during wet season were measured by skewness and kurtosis. With the exception of $\mathrm{Cr}, \mathrm{Cd}, \mathrm{Pb}$, and $\mathrm{Cu}$, all physicochemical characteristics and HM concentrations in GW exhibited positive skewness, meaning the right side is longer than the left side. This indicates that an asymmetry distribution with a positive skewness tends to be less concentrated. All parameters have a negative kurtosis value, which suggests that the distribution of the datasets was flatter than a normal distribution.

The HM concentrations in GW during the wet season were assessed in comparison to the PNSDW 2017 and WHO Standards for Drinking Water. Only the mean Ni content was below the PNSDW 2017 and WHO drinking water requirements. $\mathrm{Cr}, \mathrm{Cd}, \mathrm{Fe}, \mathrm{Mn}$, $\mathrm{Pb}, \mathrm{Zn}$, and $\mathrm{Cu}$ values were above the permissible limits set by PNSDW 2017 and WHO. Furthermore, some sites have concentrations that were far higher than the permissible level.

A Pearson's Correlation Matrix (PCM) was utilized to establish the level of correlation between GW HMs and physicochemical properties in the island province of Marinduque, with the goal of identifying a potential source of the HMs. Table 5 shows the metals correlation matrix that was generated during the dry season. $\mathrm{Cd}(\mathrm{r}=0.72), \mathrm{Ni}(\mathrm{r}=0.69)$, and $\mathrm{Pb}(\mathrm{r}=0.81)$ were all highly linked with chromium. Cadmium and $\mathrm{Ni}(\mathrm{r}=0.78)$, $\mathrm{Cd}$ and $\mathrm{Pb}(\mathrm{r}=0.83)$, and $\mathrm{Ni}$ and $\mathrm{Pb}(\mathrm{r}=0.77)$ showed substantial positive associations. Positive significant correlations imply that these metals have a shared origin, were mutually dependent, and behaved similarly throughout transport [100].

The correlation analysis for water quality parameters during the wet season is shown in Table 6 and illustrated in Figure 5. For the physicochemical characteristics, the EC was observed to have a positive correlation to TDS which agreed to the findings of Manikandan et al. in 2020 [101]. A significant connection was found between $\mathrm{Cr}$ and $\mathrm{Cd}$, as well as $\mathrm{Cu}$ and $\mathrm{Zn}$, for the HMs in GW during the wet season. This indicated a possible shared source for these HMs. Moreover, these correlations were in agreement with the findings of Kumar et al. in 2012 [102] and Mansouri et al. in 2012 [103]. 
Table 5. Correlation analysis of HMs in GW during dry season.

\begin{tabular}{|c|c|c|c|c|c|c|c|c|c|c|c|c|}
\hline & Temp & $\mathrm{pH}$ & EC & TDS & $\mathrm{Cr}$ & $\mathrm{Cd}$ & $\mathrm{Fe}$ & Mn & $\mathrm{Ni}$ & $\mathrm{Pb}$ & $\mathrm{Zn}$ & $\mathrm{Cu}$ \\
\hline Temp & 1.00 & -0.20 ** & $0.24 * *$ & $-0.18^{* *}$ & -0.06 & $-0.21 * *$ & $-0.19 * *$ & -0.09 & 0.003 & -0.11 * & -0.04 & $0.13 *$ \\
\hline $\mathrm{pH}$ & & 1.00 & 0.06 & $-0.15^{* *}$ & -0.07 & -0.09 & -0.12 * & $0.18^{* *}$ & $-0.17^{* *}$ & $-0.18^{* *}$ & 0.03 & -0.08 \\
\hline EC & & & 1.00 & 0.30 ** & -0.05 & $-0.28 * *$ & 0.05 & $0.12 *$ & $-0.18 * *$ & $-0.23^{* *}$ & -0.04 & 0.10 \\
\hline TDS & & & & 1.00 & 0.04 & 0.003 & 0.11 * & 0.08 & $-0.17 * *$ & -0.01 & 0.09 & $-0.20 * *$ \\
\hline $\mathrm{Cr}$ & & & & & 1.00 & $0.72 * *$ & 0.01 & 0.001 & $0.69 * *$ & 0.81 ** & 0.09 & $0.33^{* *}$ \\
\hline $\mathrm{Cd}$ & & & & & & 1.00 & $-0.13 *$ & 0.05 & $0.78^{* *}$ & $0.83 * *$ & $-0.11 *$ & $0.27 * *$ \\
\hline $\mathrm{Fe}$ & & & & & & & 1.00 & $0.12 *$ & $-0.12 *$ & -0.04 & $0.50 * *$ & -0.07 \\
\hline $\mathrm{Mn}$ & & & & & & & & 1.00 & 0.07 & 0.02 & $0.14^{* *}$ & -0.09 \\
\hline $\mathrm{Ni}$ & & & & & & & & & 1.00 & $0.77 * *$ & -0.09 & $0.38^{* *}$ \\
\hline $\mathrm{Pb}$ & & & & & & & & & & 1.00 & -0.03 & $0.41^{* *}$ \\
\hline $\mathrm{Zn}$ & & & & & & & & & & & 1.00 & -0.08 \\
\hline $\mathrm{Cu}$ & & & & & & & & & & & & 1.00 \\
\hline
\end{tabular}

** Correlation is significant at the 0.01 level (two-tailed); ${ }^{*}$ Correlation is significant at the 0.05 level (two-tailed).

Table 6. Correlation analysis of HMs in GW during wet season.

\begin{tabular}{|c|c|c|c|c|c|c|c|c|c|c|c|c|}
\hline & Temp & $\mathrm{pH}$ & EC & TDS & $\mathrm{Cr}$ & $\mathrm{Cd}$ & $\mathrm{Fe}$ & Mn & $\mathrm{Ni}$ & $\mathrm{Pb}$ & $\mathrm{Zn}$ & $\mathrm{Cu}$ \\
\hline Temp & 1.00 & 0.04 & $-0.22 * *$ & $-0.22 * *$ & 0.01 & $0.11 *$ & $-0.40 * *$ & $0.22 * *$ & -0.09 & $-0.17 * *$ & -0.07 & 0.03 \\
\hline $\mathrm{pH}$ & & 1.00 & -0.11 * & -0.06 & $0.23^{* *}$ & 0.15 ** & -0.06 & $0.36^{* *}$ & $-0.36^{* *}$ & $-0.28^{* *}$ & $0.33^{* *}$ & $0.49^{* *}$ \\
\hline EC & & & 1.00 & $0.49^{* *}$ & $-0.30 * *$ & -0.10 & 0.07 & $-0.52 * *$ & $-0.15^{* *}$ & $0.25^{* *}$ & $0.17^{* *}$ & 0.03 \\
\hline TDS & & & & 1.00 & 0.04 & $0.18^{* *}$ & 0.06 & $-0.19 * *$ & $0.18^{* *}$ & 0.04 & -0.07 & -0.08 \\
\hline $\mathrm{Cr}$ & & & & & 1.00 & $0.40 * *$ & -0.02 & $0.24^{* *}$ & $0.17^{* *}$ & 0.07 & 0.02 & $0.12^{*}$ \\
\hline $\mathrm{Cd}$ & & & & & & 1.00 & 0.09 & $0.19^{* *}$ & 0.26 ** & $0.25 * *$ & $0.19^{* *}$ & $0.27 * *$ \\
\hline $\mathrm{Fe}$ & & & & & & & 1.00 & -0.08 & -0.01 & $0.17^{* *}$ & $0.22 * *$ & 0.04 \\
\hline Mn & & & & & & & & 1.00 & $-0.24^{* *}$ & $-0.36^{* *}$ & -0.12 * & 0.05 \\
\hline $\mathrm{Ni}$ & & & & & & & & & 1.00 & $0.19^{* *}$ & $-0.29 * *$ & $-0.21 * *$ \\
\hline $\mathrm{Pb}$ & & & & & & & & & & 1.00 & 0.05 & -0.07 \\
\hline $\mathrm{Zn}$ & & & & & & & & & & & 1.00 & $0.49^{* *}$ \\
\hline $\mathrm{Cu}$ & & & & & & & & & & & & 1.00 \\
\hline
\end{tabular}

${ }^{* *}$ Correlation is significant at the 0.01 level (two-tailed); ${ }^{*}$ Correlation is significant at the 0.05 level (two-tailed).

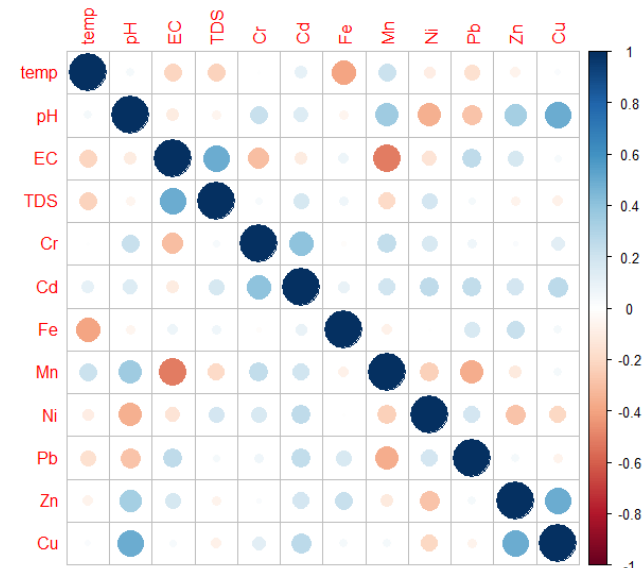

(a)

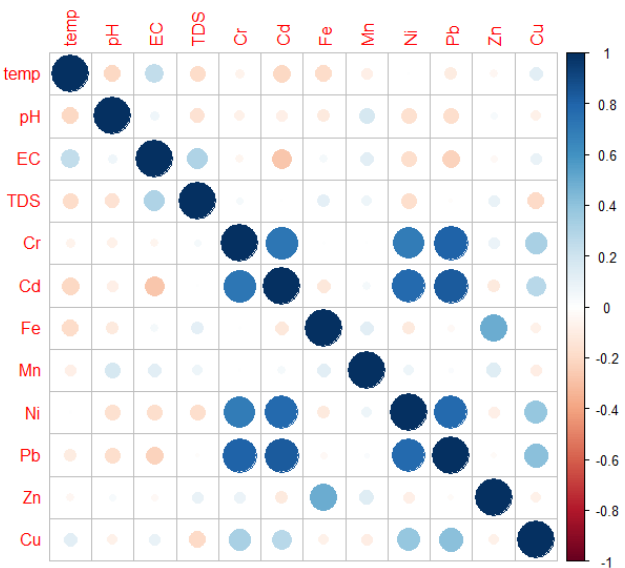

(b)

Figure 5. Correlation matrix plot of GW in the study area during (a) dry and (b) wet season.

\subsection{NN-PSO Simulation Results}

The hybrid NN-PSO was utilized to improve the efficiency and robustness of spatial interpolation mapping of GW quality. The proposed method was evaluated by considering different internal characteristics of the network. The Levenberg-Marquardt method was used as the training algorithm, and the hyperbolic tangent sigmoid was used as the transfer function for the input layer (IL) to hidden layer (HL) and HL to output layer (OL) in the hybrid NN-PSO informed spatial interpolation approaches. The results of the NN-PSO simulation for the dry and wet season GW quality parameters are presented in Tables 7 and 8 . 
Table 7. NN-PSO simulation results for GW quality parameters during the dry season.

\begin{tabular}{cccccccc}
\hline & Hidden & $\begin{array}{c}\text { No. of } \\
\text { Neurons }\end{array}$ & $\begin{array}{c}\text { No. of It- } \\
\text { Particles }\end{array}$ & $\begin{array}{c}\text { Elapsed } \\
\text { erations }\end{array}$ & $\begin{array}{c}\text { Time } \\
\text { (sec) }\end{array}$ & MSE & \multicolumn{2}{c}{ R } \\
\cline { 6 - 8 } & & & & & Validation & Testing \\
\hline $\mathrm{Temp}$ & 22 & 7 & 2000 & 214.984 & 0.11275 & 0.99988 & 0.99925 \\
$\mathrm{pH}$ & 27 & 5 & 2000 & 253.880 & 0.01176 & 0.98051 & 0.95432 \\
$\mathrm{EC}$ & 24 & 5 & 2000 & 215.542 & 0.03365 & 0.99993 & 0.99994 \\
$\mathrm{TDS}$ & 28 & 7 & 2000 & 220.718 & 0.00985 & 0.99061 & 0.99917 \\
$\mathrm{Cr}$ & 28 & 8 & 2000 & 147.899 & 0.00032 & 0.99958 & 0.98867 \\
$\mathrm{Cd}$ & 20 & 8 & 2000 & 110.308 & 0.00031 & 0.99669 & 0.98496 \\
$\mathrm{Fe}$ & 29 & 10 & 2000 & 142.590 & 0.01073 & 0.99683 & 0.99737 \\
$\mathrm{Mn}$ & 26 & 9 & 2000 & 146.913 & 0.00255 & 0.99788 & 0.99620 \\
$\mathrm{Ni}$ & 22 & 1 & 2000 & 115.371 & 0.00050 & 0.99987 & 0.99995 \\
$\mathrm{~Pb}$ & 20 & 4 & 2000 & 115.961 & 0.00058 & 0.99949 & 0.99992 \\
$\mathrm{Zn}$ & 27 & 7 & 2000 & 110.420 & 0.00087 & 0.99972 & 0.99967 \\
$\mathrm{Cu}$ & 21 & 6 & 2000 & 138.813 & 0.00153 & 0.99985 & 0.99960 \\
\hline
\end{tabular}

Table 8. NN-PSO simulation results for GW quality parameters during the wet season.

\begin{tabular}{cccccccc}
\hline & $\begin{array}{c}\text { Hidden } \\
\text { Neurons }\end{array}$ & $\begin{array}{c}\text { No. of } \\
\text { Particles }\end{array}$ & $\begin{array}{c}\text { No. of It- } \\
\text { erations }\end{array}$ & $\begin{array}{c}\text { Elapsed } \\
\text { Time (s) }\end{array}$ & MSE & \multicolumn{2}{c}{ R } \\
\cline { 6 - 8 } & & & & & Validation & Testing \\
\hline Temp & 23 & 6 & 2000 & 226.663 & 0.73235 & 0.99440 & 0.99161 \\
$\mathrm{pH}$ & 23 & 6 & 2000 & 218.558 & 0.04694 & 0.99396 & 0.97383 \\
$\mathrm{EC}$ & 21 & 9 & 2000 & 223.412 & 0.02622 & 0.99755 & 0.99990 \\
$\mathrm{TDS}$ & 26 & 1 & 2000 & 205.010 & 0.00672 & 0.99360 & 0.99434 \\
$\mathrm{Cr}$ & 25 & 9 & 2000 & 147.159 & 0.00153 & 0.99948 & 0.99912 \\
$\mathrm{Cd}$ & 28 & 8 & 2000 & 145.022 & 0.00088 & 0.99998 & 0.99980 \\
$\mathrm{Fe}$ & 29 & 7 & 2000 & 147.002 & 0.18100 & 0.99992 & 0.99999 \\
$\mathrm{Mn}$ & 24 & 7 & 2000 & 157.724 & 0.01737 & 0.99938 & 0.99985 \\
$\mathrm{Ni}$ & 30 & 6 & 2000 & 155.655 & 0.15711 & 0.99498 & 0.98943 \\
$\mathrm{~Pb}$ & 25 & 4 & 2000 & 109.265 & 0.00177 & 0.99998 & 0.98257 \\
$\mathrm{Zn}$ & 29 & 8 & 2000 & 178.172 & 0.17360 & 0.99305 & 0.99238 \\
$\mathrm{Cu}$ & 27 & 4 & 2000 & 174.482 & 0.00494 & 0.99882 & 0.99937 \\
\hline
\end{tabular}

The results and efficiency of the NN-PSO simulation for dry and wet season GW quality parameters showed excellent results, as evidenced by the extremely low MSE (ideal value is zero) and extremely high $\mathrm{R}$ values for internal validation and testing of the $\mathrm{NN}$ PSO models (ideal value is one). These NN-PSO models informed the spatial interpolation techniques which improved the accuracy and performance of the GW quality maps. The R plots of the NN-PSO simulation for the physicochemical parameters and HM concentrations during the dry and wet season are presented in Figures A1-A6 in Appendix A.

\subsection{NN-PSO Informed Spatial Interpolation Techniques for GW Quality Mapping}

The performance of the NN-PSO informed spatial interpolation approaches for GW quality mapping was evaluated via cross validation, with MAE and R values utilized in order to assess the prediction capability of the various interpolation techniques. The approach that produced the lowest MAE value and the greatest $\mathrm{R}$ value was regarded the best. The accuracy and effectiveness of the techniques employed to interpolate GW quality during the dry season are displayed in Figures 6 and 7. The complete values for the performance of the different interpolation techniques during the dry season are shown in Table A1 of Appendix B. 


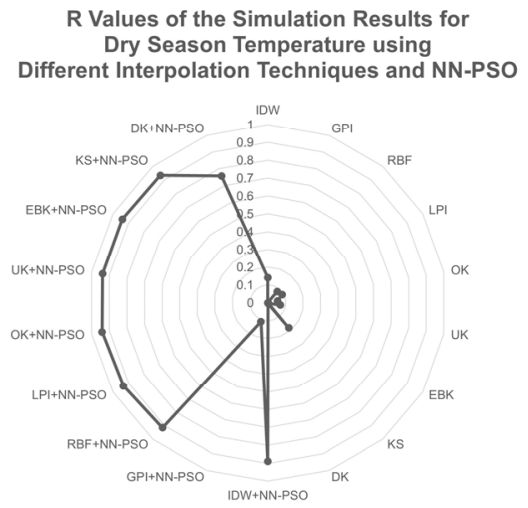

(a)

$R$ Values of the Simulation Results for Dry Season Electrical Conductivity using Different Interpolation Techniques and NN-PSO

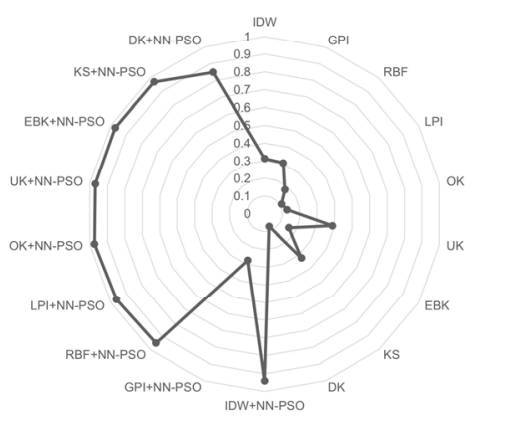

(c)

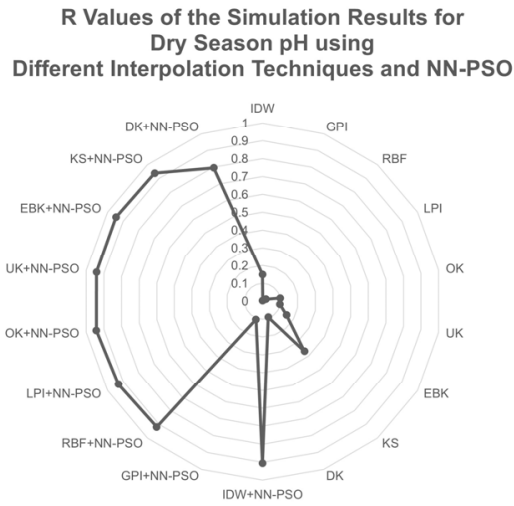

(b)

R Values of the Simulation Results for Dry Season Total Dissolved Solids using Different Interpolation Techniques and NN-PSO

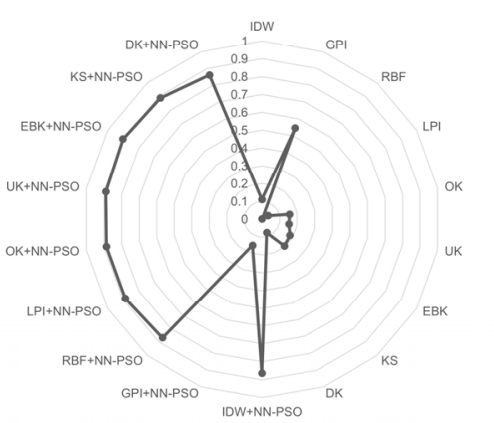

(d)

Figure 6. $\mathrm{R}$ values of the simulation results for the physicochemical characteristics during dry season using different interpolation techniques and NN-PSO: (a) temperature; (b) pH; (c) EC; and (d) TDS. These figures illustrate the performance and efficiency of interpolation techniques for mapping the physical properties of GW during the dry season.

Various interpolation techniques were applied in order to evaluate the spatial variability of GW quality in the province of Marinduque during the dry season, including IDW, GPI, RBF, LPI, OK, UK, EBK, DK, and KS. Moreover, these interpolation techniques were likewise assessed after being informed and integrated with NN-PSO.

Physicochemical properties and HM concentrations of GW were mapped and analyzed using various interpolation approaches throughout the dry season. Except for Nickel (Ni), which had the best mapping prediction performance using NN-PSO informed radial basis functions, NN-PSO informed geostatistical techniques and OK and EBK methods, in particular, were the best approaches for mapping the GW quality during the dry season. The performance of the best interpolation technique was manifested through its lowest MAE and highest $R$ values.

Figure 6 illustrates that the NN-PSO informed OK model had the best mapping prediction for GW temperature and EC during dry season. The OK-NN-PSO method had the least MAE and highest $R$ value which is significantly higher than the best method observed without NN-PSO. The EBK-NN-PSO method was observed to have the best prediction performance for groundwater $\mathrm{pH}$ and TDS as evident to its lowest MAE and highest $R$ value. Similarly, these validation criteria have significant improvement than compared to the interpolation methods that were not NN-PSO informed.

During the dry season, HM concentrations in GW were also mapped and evaluated by using several spatial interpolations approaches as shown in Figure 7. Using the NNPSO informed Empirical Bayesian Kriging technique (EBK-NN-PSO), the best mapping prediction performance was found for $\mathrm{Cr}, \mathrm{Cd}, \mathrm{Fe}, \mathrm{Pb}, \mathrm{Zn}$, and $\mathrm{Cu}$. 


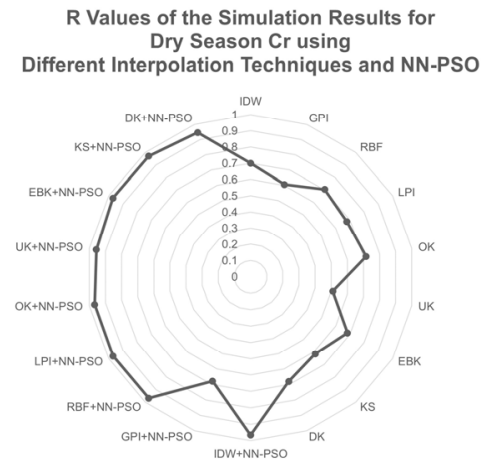

(a)

$R$ Values of the Simulation Results for Different Interpolation Techniques and NN-PSO

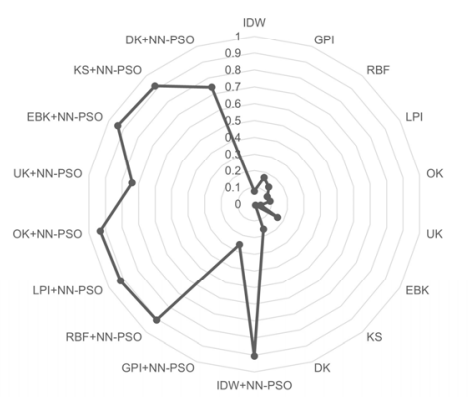

(c)

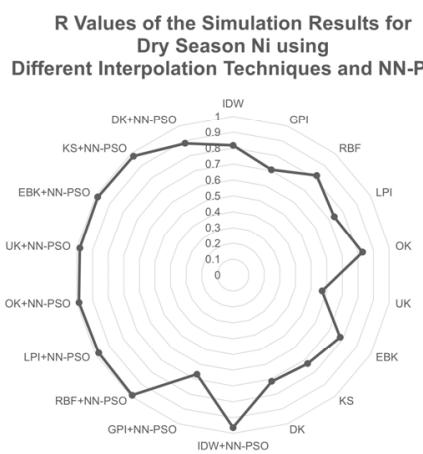

(e)

$R$ Values of the Simulation Results for Dry Season $\mathrm{Zn}$ using

Different Interpolation Techniques and NN-PSO

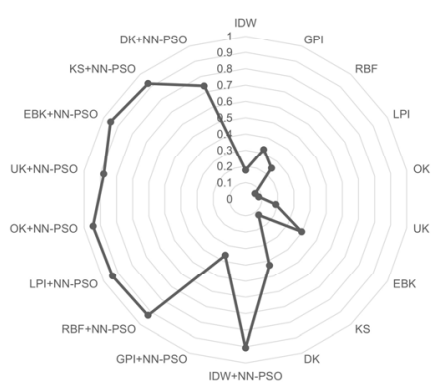

(g)

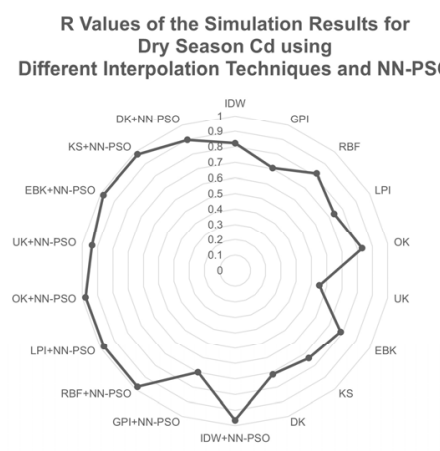

(b)

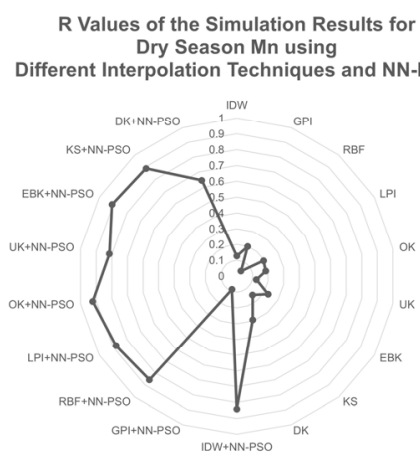

(d)

$R$ Values of the Simulation Results for Different Interpolation Techniques and NN-PSO

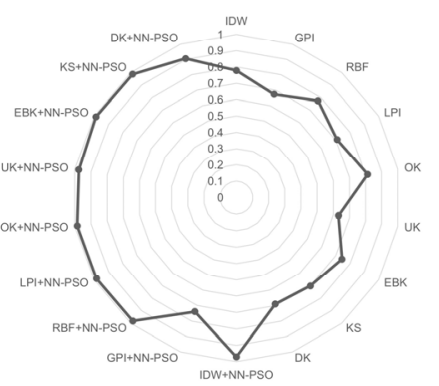

(f)

$R$ Values of the Simulation Results for Different Interpolation Techniques and NN-PSO

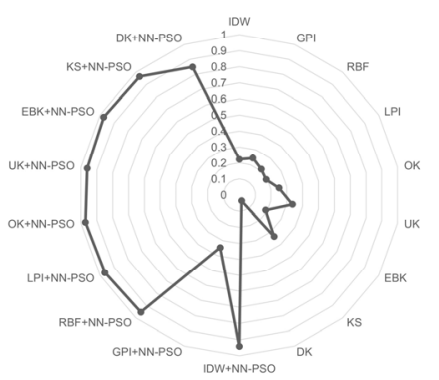

(h)

Figure 7. $\mathrm{R}$ values of the simulation results for $\mathrm{HM}$ concentrations during dry season using different interpolation techniques and NN-PSO: (a) Cr; (b) Cd; (c) Fe; (d) Mn; (e) Ni; (f) Pb; (g) Zn; and (h) Cu.

Among the interpolations employed, the EBK+NN-PSO technique for mapping $\mathrm{Cr}, \mathrm{Cd}$, $\mathrm{Fe}, \mathrm{Pb}, \mathrm{Zn}$, and $\mathrm{Cu}$ has the lowest MAE. The $\mathrm{R}$ value of the NN-PSO informed EBK method used for $\mathrm{Cr}$ increased by $35.61 \%, \mathrm{Cd}=17.91 \%$, and $\mathrm{Pb}=21.65 \%$. Furthermore, $\mathrm{R}$ values 
of $\mathrm{Fe}, \mathrm{Zn}$, and $\mathrm{Cu}$ improved by 5.6, 2.4, and 2.9 times, respectively. Manganese (Mn) and Nickel (Ni) were observed to have the best prediction performance using NN-PSO informed OK and RBF method, respectively. Correspondingly, the performance of these models for $\mathrm{Mn}$ and Ni was observed to have the lowest MAE among the interpolation techniques utilized and 3.1 and 1.2 times higher than compared to interpolation techniques without NN-PSO. The NN-PSO informed dry season GW physicochemical characteristics and HM concentration map of Marinduque are presented in Figures A7 and A8 of Appendix C.

The NN-PSO informed geostatistical approaches, comprising OK and EBK, were shown to be the optimum method for the wet season GW physicochemical properties, with the lowest MAE and highest $\mathrm{R}$. For groundwater temperature and $\mathrm{pH}, \mathrm{OK}$ was the best technique, whereas EBK was the best method for EC and TDS. The NN-PSO informed OK was the best among the interpolation techniques integrated with NN-PSO and had an R observed to be 3.9 times greater than compared to the best interpolation method without NN-PSO. Additionally, the other physicochemical parameters including GW pH, EC, and TDS were observed to have an $\mathrm{R}$ value of 2.7, 4.3, and 3.4 times higher than the spatial interpolation methods with NN-PSO integration. The performance of the different spatial interpolation techniques for the parameters observed during the wet season is presented in Figures 8 and 9. As illustrated in Figure 8 , the OK+NN-PSO model provided the most accurate mapping forecast for GW temperature and $\mathrm{pH}$ during wet season. Among the observed spatial interpolation techniques for temperature and $\mathrm{pH}$, the $\mathrm{OK}+\mathrm{NN}-\mathrm{PSO}$ approach achieved the highest $R$ value and the lowest MAE. The EBK+NN-PSO approach had shown the greatest prediction performance for GW EC and TDS during wet season.

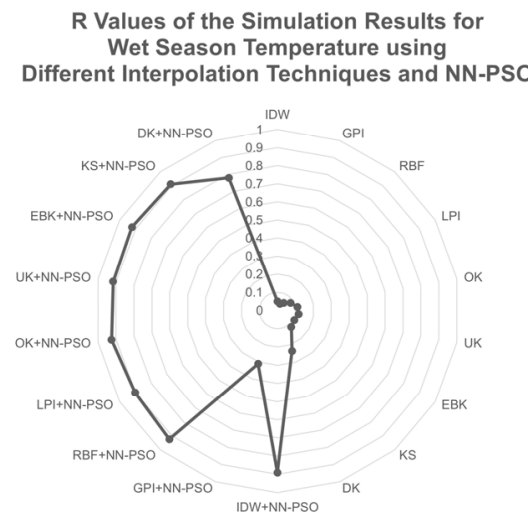

(a)

$R$ Values of the Simulation Results for Wet Season Electrical Conductivity using Different Interpolation Techniques and NN-PSO

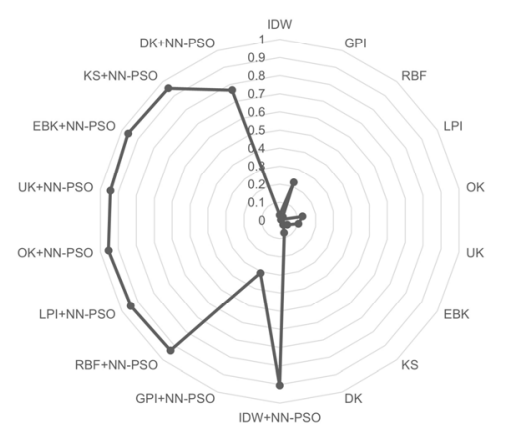

(c)

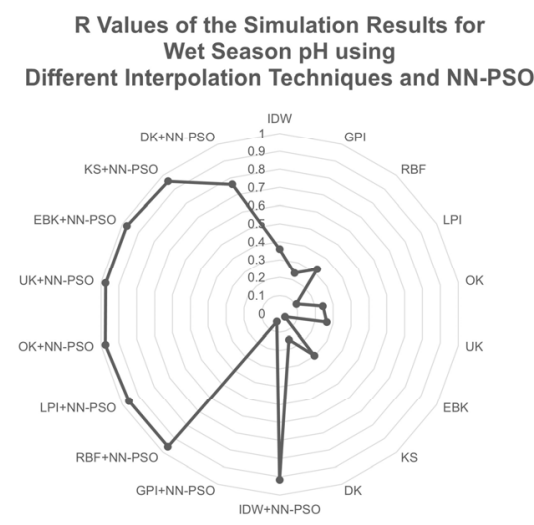

(b)

$R$ Values of the Simulation Results for Wet Season Total Dissolved Solids using Different Interpolation Techniques and NN-PSO

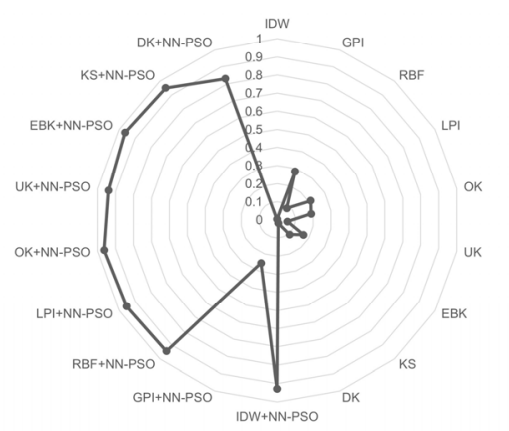

(d)

Figure 8. R values of the simulation results for the physicochemical characteristics during wet season using different interpolation techniques and NN-PSO: (a) temperature; (b) pH; (c) EC; and (d) TDS. 


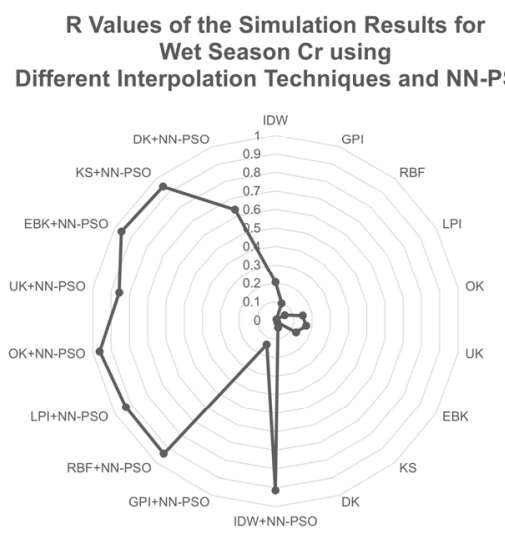

(a)

$R$ Values of the Simulation Results fo Wet Season $\mathrm{Fe}$ using Different Interpolation Techniques and NN-PSO

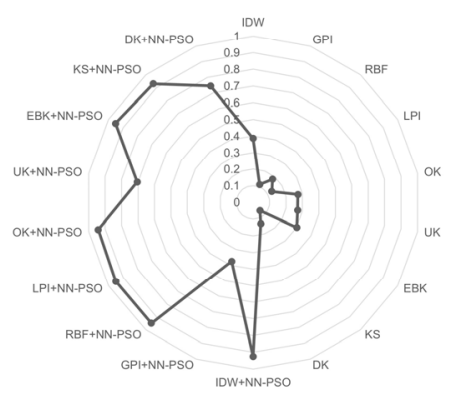

(c)

$R$ Values of the Simulation Results for Wet Season Ni using Different Interpolation Techniques and NN-PSO

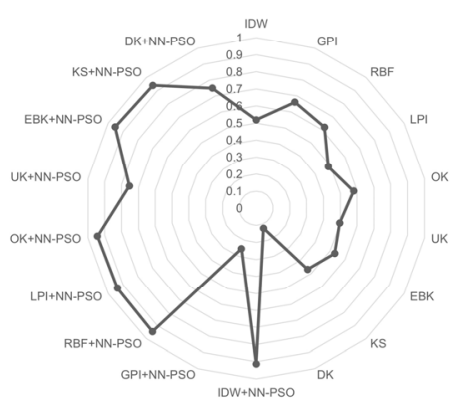

(e)

$R$ Values of the Simulation Results for Wet Season $\mathrm{Zn}$ using Different Interpolation Techniques and NN-PSO

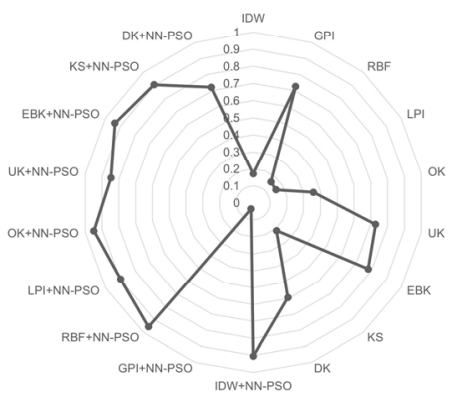

(g)
$R$ Values of the Simulation Results for Wet Season Cd using

Different Interpolation Techniques and NN-PSO

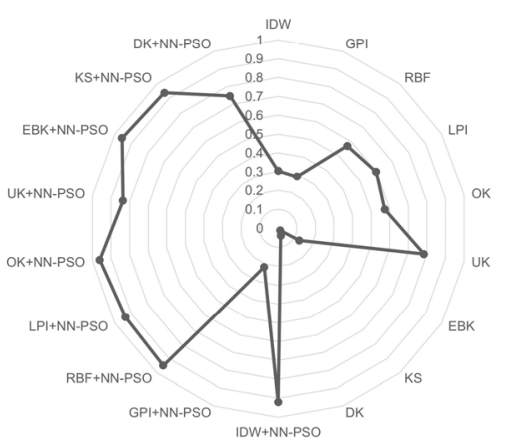

(b)

$R$ Values of the Simulation Results for Wet Season Mn using

Different Interpolation Techniques and NN-PSO

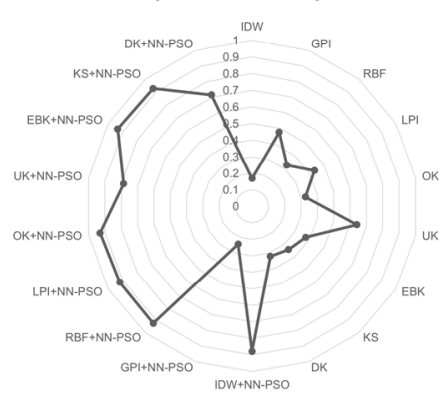

(d)

R Values of the Simulation Results for Wet Season $\mathrm{Pb}$ using Different Interpolation Techniques and NN-PSO

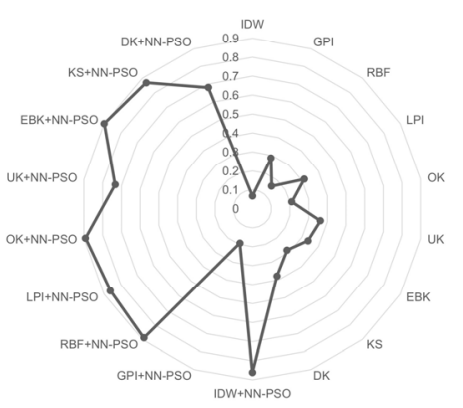

(f)

$R$ Values of the Simulation Results for Wet Season Cu using Different Interpolation Techniques and NN-PSO

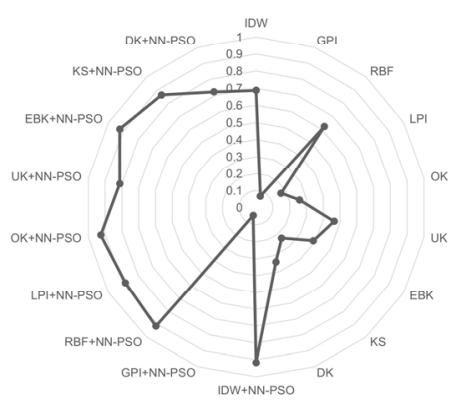

(h)

Figure 9. $\mathrm{R}$ values of the simulation results for $\mathrm{HM}$ concentrations during wet season using different interpolation techniques and NN-PSO: (a) Cr; (b) Cd; (c) Fe; (d) Mn; (e) Ni; (f) Pb; (g) Zn; and (h) Cu. 
As illustrated by Figure 9, EBK+NN-PSO provided the best mapping prediction performance for $\mathrm{Fe}, \mathrm{Mn}, \mathrm{Ni}, \mathrm{Pb}$, and $\mathrm{Zn}$. OK+NN-PSO provided the best mapping prediction performance for $\mathrm{Cr}, \mathrm{Cd}$, and $\mathrm{Cu}$. RBF+NN-PSO provided the best mapping prediction performance for $\mathrm{Zn}$. Table A2 in Appendix B elaborates the complete values for the performance of the various interpolation methods for the wet season.

The HM concentration during the wet season was mapped using the different interpolation techniques with and without the integration of NN-PSO. Chromium $(\mathrm{Cr}), \mathrm{Cadmium}$ $(\mathrm{Cr})$, and Copper $(\mathrm{Cu})$ concentrations were mapped using the best method observed which is the integration of Ordinary Kriging (OK) and NN-PSO. The OK+NN-PSO technique had the lowest MAE, and its $\mathrm{R}$ value was 4.7, 1.2, and 1.3 times greater than the maximum $\mathrm{R}$ value found for the interpolation method without NN-PSO integration. The metals Fe, $\mathrm{Mn}, \mathrm{Ni}$, and $\mathrm{Pb}$ have the best prediction performance based on MAE and $\mathrm{R}$ utilizing Empirical Bayesian kriging (EBK) combined with NN-PSO. When compared to interpolation approaches without NN-PSO integration, the EBK-NN-PSO method provided the lowest MAE and $R$ values, which were 2.5, 1.5, 1.4, and 2.4 times higher. The spatial interpolation maps with the best prediction performance for the physicochemical characteristics and HM concentrations are presented in Figures A9-A11 of Appendix C.

The summary of the cross-validation performance of the models for the physicochemical parameters and the HM concentrations both for dry and wet season is exhibited in Table 9.

Table 9. Summary of the cross-validation performance of the models for the physicochemical parameters and the HM concentrations both for dry and wet season.

\begin{tabular}{ccccc}
\hline Parameter & Season & $\begin{array}{c}\text { Governing } \\
\text { Interpolation Method }\end{array}$ & MAE & R \\
\hline Temperature & Dry & OK+NN-PSO & 0.002000 & 0.941 \\
$\mathrm{pH}$ & Dry & EBK+NN-PSO & 0.001000 & 0.945 \\
$\mathrm{EC}$ & Dry & OK+NN-PSO & 0.002000 & 0.974 \\
$\mathrm{TDS}$ & Dry & EBK+NN-PSO & 0.001000 & 0.901 \\
$\mathrm{Cr}$ & Dry & EBK+NN-PSO & 0.000070 & 0.971 \\
$\mathrm{Cd}$ & Dry & EBK+NN-PSO & 0.000065 & 0.981 \\
$\mathrm{Fe}$ & Dry & EBK+NN-PSO & 0.045000 & 0.940 \\
$\mathrm{Mn}$ & Dry & OK+NN-PSO & 0.005000 & 0.922 \\
$\mathrm{Ni}$ & Dry & RBF+NN-PSO & 0.000200 & 0.991 \\
$\mathrm{~Pb}$ & Dry & EBK+NN-PSO & 0.000100 & 0.989 \\
$\mathrm{Zn}$ & Dry & EBK+NN-PSO & 0.017000 & 0.951 \\
$\mathrm{Cu}$ & Dry & EBK+NN-PSO & 0.000200 & 0.974 \\
$\mathrm{Temperature}$ & Wet & OK+NN-PSO & 0.004000 & 0.925 \\
$\mathrm{pH}$ & Wet & OK+NN-PSO & 0.000300 & 0.976 \\
$\mathrm{EC}$ & Wet & EBK+NN-PSO & 0.000200 & 0.962 \\
$\mathrm{TDS}$ & Wet & EBK+NN-PSO & 0.001000 & 0.964 \\
$\mathrm{Cr}$ & Wet & OK+NN-PSO & 0.000100 & 0.963 \\
$\mathrm{Cd}$ & Wet & OK+NN-PSO & 0.000100 & 0.961 \\
$\mathrm{Fe}$ & Wet & EBK+NN-PSO & 0.055000 & 0.952 \\
$\mathrm{Mn}$ & Wet & EBK+NN-PSO & 0.005000 & 0.935 \\
$\mathrm{Ni}$ & Wet & EBK+NN-PSO & 0.000050 & 0.954 \\
$\mathrm{~Pb}$ & Wet & EBK+NN-PSO & 0.000200 & 0.900 \\
$\mathrm{Zn}$ & Wet & RBF+NN-PSO & 0.019000 & 0.956 \\
$\mathrm{Cu}$ & Wet & OK+NN-PSO & 0.000200 & 0.926 \\
\hline
\end{tabular}

\section{Discussion}

Based on the results, the use of the hybrid neural network-particle swarm optimization method in spatial interpolation was able to address the sampling density issue experienced in water quality monitoring. It provides solutions on data gaps when the spatial distribution map of GW quality becomes available by having simple water parameter such as $\mathrm{pH}$ [104]. The impact of this research is emphasizes on prediction improvement for 
mapping specific features and water quality parameters and ease in GW quality monitoring. Furthermore, it contributes to solutions in data gaps when processed data are necessary.

The application of a range of machine learning techniques, as well as the combination and comparison of these approaches, resulted in a larger pool of potential environmental monitoring systems. The integration of machine learning techniques to spatial interpolation techniques have been implemented in several studies including Least Squares Support Vector Machine (LSSVM) and Population-based Incremental Learning to Ordinary Kriging (OK) [105], Random Forest (RF) to IDW and OK [106], Deep Neural Network (DNN) to Ordinary Kriging (OK) [107], Decision Tree to Kriging and Inverse Distance Weighting [108], and Non-linear AutoRegressive eXogenous (NARX) model to Geographic Information System [109].

A different method was integrated relative to spatial interpolation techniques in this research study. The use of the NN-PSO methodology with the capability of both prediction and optimization was utilized to enhance the prediction capacity of spatial interpolation methods. The findings of the cross validation of the HM concentration and physicochemical parameters showed that the spatial interpolation methods integrated with NN-PSO were the best method as manifested to its lowest MAE and highest $R$ value. The governing interpolation methods were mostly under the geostatistical methods which integrated with NN-PSO including OK (OK+NN-PSO) and EBK (EBK+NN-PSO) method. Moreover, some $\mathrm{HMs}$ such as $\mathrm{Ni}$ (dry season) and Zn (wet season) have best performance using NN-PSO informed radial basis functions (RBF-NN-PSO). The findings of this study in reference to the performance of the NN-PSO informed spatial interpolation techniques agreed with the study of Li et al. [110], wherein they confirm that the integration of machine learning techniques produces more superior performance in the spatial interpolation method than compared to spatial interpolation methods without machine learning integration. The NNPSO integration relative to spatial integration techniques addressed the issue in sampling density and was able to improve the performance of the spatial interpolation methods.

\section{Conclusions}

The objective of this research is to improve the mapping prediction capability of spatial interpolation algorithms by using an NN-PSO technique. It analyzed interpolation methods and mapping for physicochemical parameters such as temperature, $\mathrm{pH}, \mathrm{TDS}$, and EC, as well as mapping of HM concentrations in GW. This technique comprises three spatial interpolation methods such as deterministic, geostatistical, and interpolation with barriers with neuro-particle swarm optimization guided interpolation approaches. The measurement criteria for the best method were the least MAE and the highest $R$ value.

The results recorded the governing interpolation techniques during the dry and wet season. The OK+NN-PSO method was recorded as best performing for temperature and EC during dry season, while EBK+NN-PSO for $\mathrm{pH}$ and TDS. The best methods during wet season were OK+NN-PSO for temperature and $\mathrm{pH}$ and $\mathrm{EBK}+\mathrm{NN}-\mathrm{PSO}$ for $\mathrm{EC}$ and TDS. These methods have the highest $R$ and lowest MAE among the spatial interpolation techniques observed. The best methods for mapping physico-chemical characteristics were found to have the least MAE and $\mathrm{R}$ values ranging from 1.7 to 5.6 times higher than the interpolation techniques without NN-PSO integration.

The HM concentration maps during the dry season were observed to have the best performance using EBK+NN-PSO for $\mathrm{Cr}, \mathrm{Cd}, \mathrm{Fe}, \mathrm{Pb}, \mathrm{Zn}$, and $\mathrm{Cu}$ while $\mathrm{RBF}+\mathrm{NN}-\mathrm{PSO}$ was the best method for Ni mapping. The best method during the wet season was found to be $\mathrm{OK}+\mathrm{NN}-\mathrm{PSO}$ for $\mathrm{Cr}, \mathrm{Cd}$, and $\mathrm{Cu}$; EBK+NN-PSO for $\mathrm{Fe}, \mathrm{Mn}, \mathrm{Ni}$, and $\mathrm{Pb}$; and $\mathrm{RBF}+\mathrm{NN}-\mathrm{PSO}$ for $\mathrm{Zn}$. The best method for mapping the GW HM concentrations during the wet season was observed to have the least MAE and R values ranging from 1.2 times to 5.6 times greater than the best interpolation method without NN-PSO integration.

Hybrid methods in general showed better performance than compared to the nonhybrid methods. The development of these hybrid methods using NN-PSO and geostatistics provides a promising innovative approach for environmental quality monitoring 
as it improves the accuracy of predictive mapping and modelling of GW quality in an area. The integration of NN-PSO into spatial interpolation methods addresses the challenge of sample density and its effect on the spatial interpolation method's performance. It opens a new avenue for enhancing the predictive capability of spatial interpolation algorithms. On the basis of the results of this research, it can be stated that the employment of models such as NN-PSO is suitable for overcoming the challenges in spatial data processing and mapping, as well as for improving the model's predictive capabilities. The findings of the study suggest that the integration of ML techniques such as NN can be utilized in mapping GW quality as well as its application in spatio-temporal maps.

Author Contributions: Conceptualization, D.B.S.; methodology, K.L.M.D.J., D.B.S. and J.C.D.C.; software, K.L.M.D.J.; validation, K.L.M.D.J., D.B.S., E.B.C. and J.C.D.C.; formal analysis, K.L.M.D.J.; investigation, K.L.M.D.J., D.B.S. and J.C.D.C.; resources, D.B.S.; data curation, D.B.S. and K.L.M.D.J.; writing-original draft preparation, K.L.M.D.J.; writing-review and editing, D.B.S., E.B.C. and J.C.D.C.; visualization, K.L.M.D.J.; supervision, D.B.S. and J.C.D.C.; project administration, D.B.S.; funding acquisition, D.B.S. All authors have read and agreed to the published version of the manuscript.

Funding: This research was funded by the Department of Science and Technology-Philippine Council for Health Research and Development (DOST-PCHRD) and Engineering Research and Development for Technology (DOST-ERDT).

Institutional Review Board Statement: Not Applicable.

Informed Consent Statement: Not Applicable.

Data Availability Statement: All data are contained in the manuscript.

Acknowledgments: This is to acknowledge the support-in-kind of Mapua University, Marinduque Local Government Units, and Marinduque State College.

Conflicts of Interest: The authors declare no conflict of interest.

\section{Appendix A}

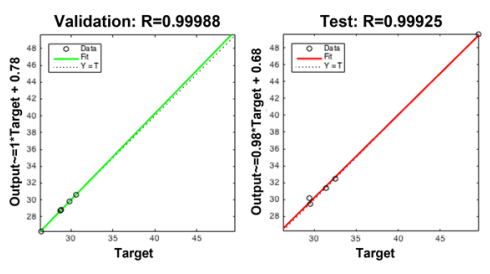

(a)

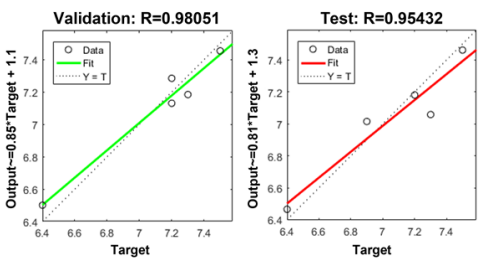

(b)

Figure A1. R value plots for validation and testing phase of the NN-PSO: (a) dry season temperature; (b) dry season $\mathrm{pH}$.

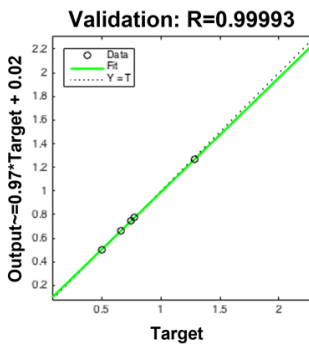

(a)

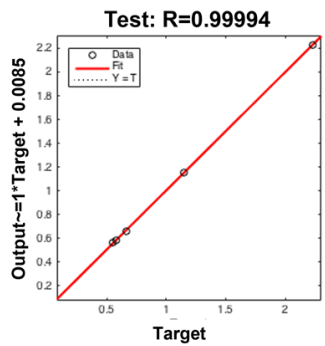

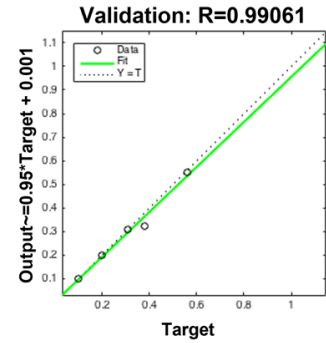

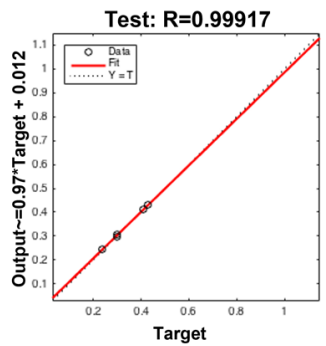

(b)

Figure A2. R value plots for validation and testing phase of the NN-PSO: (a) dry season EC; (b) dry season TDS. 


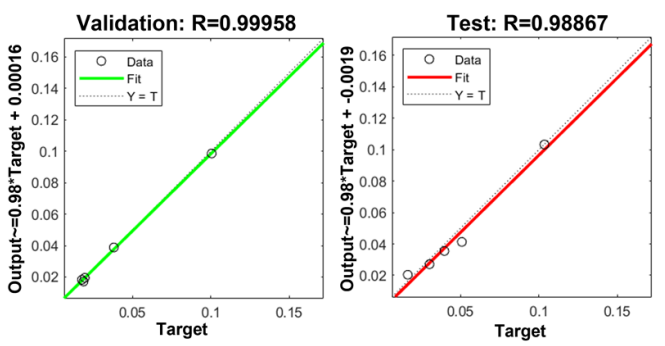

(a)
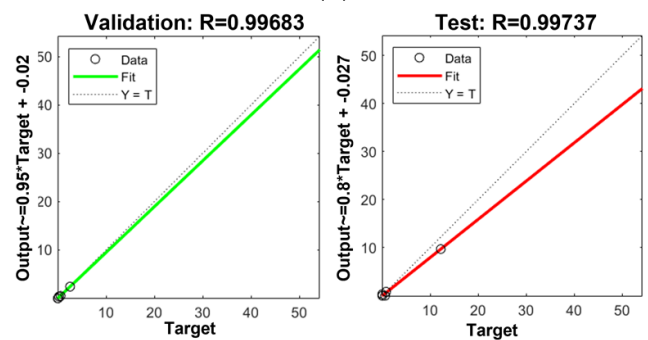

(c)

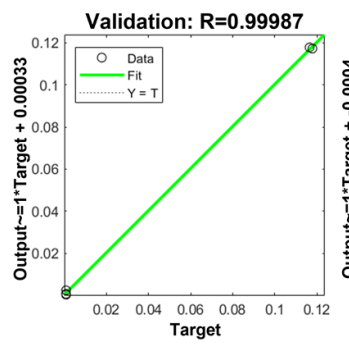

(e)
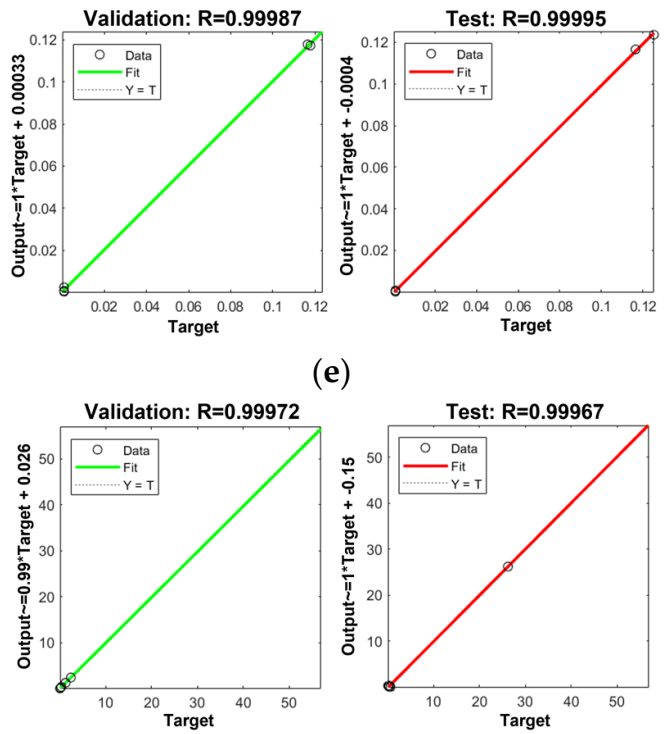

e)

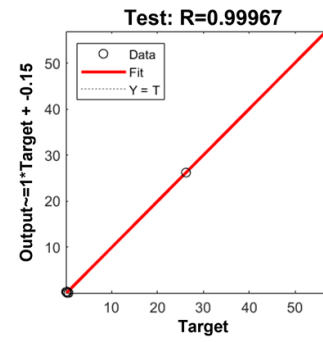

(g)

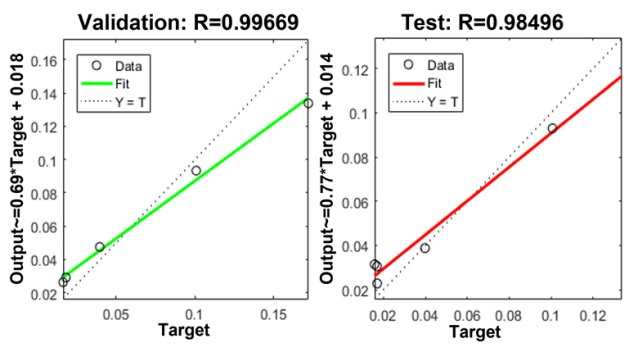

(b)

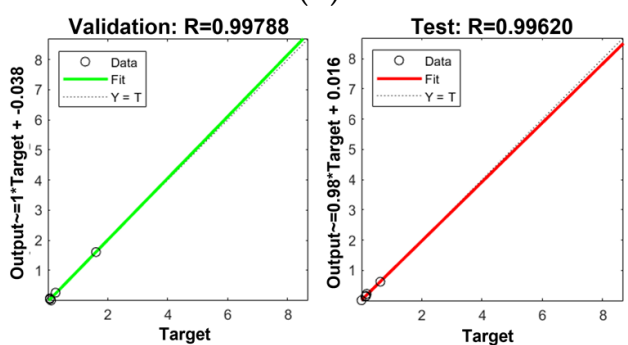

(d)
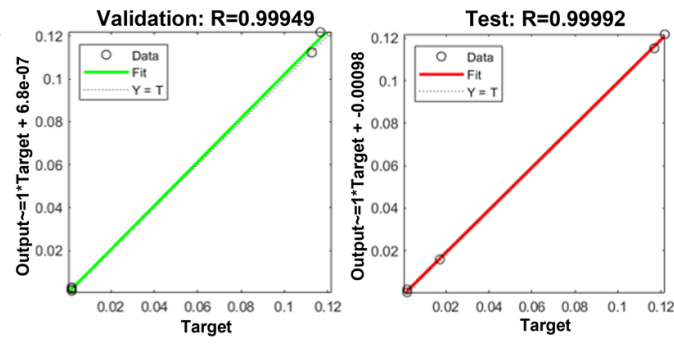

(f)
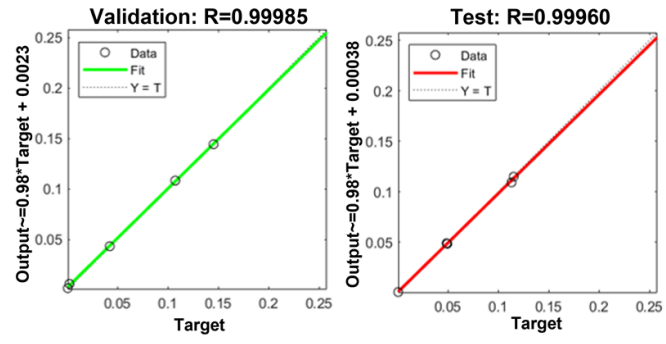

(h)

Figure A3. R value plots for validation and testing phase of the NN-PSO: (a) dry season Cr; (b) dry season $\mathrm{Cd}$; (c) dry season $\mathrm{Fe}$; (d) dry season $\mathrm{Mn}$; (e) dry season $\mathrm{Ni}$; (f) dry season $\mathrm{Pb}$; (g) dry season $\mathrm{Zn}$; (h) dry season $\mathrm{Cu}$. 


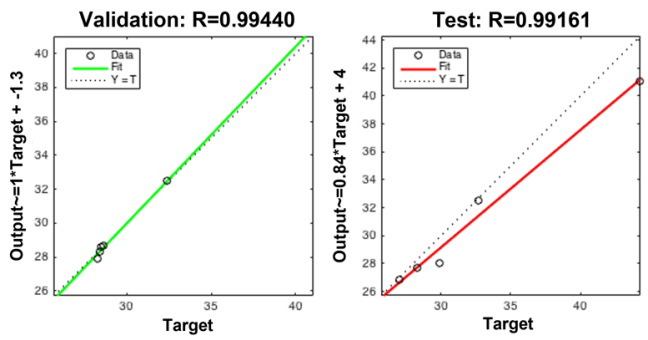

(a)
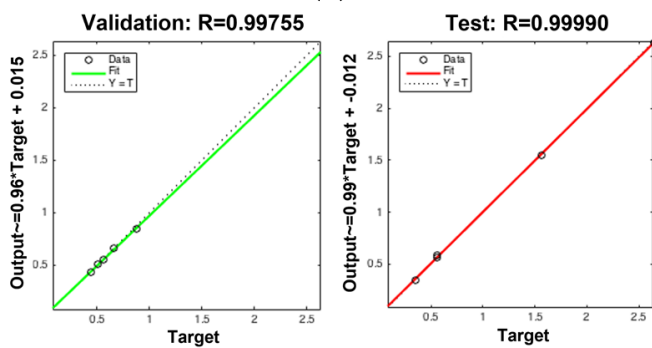

(c)
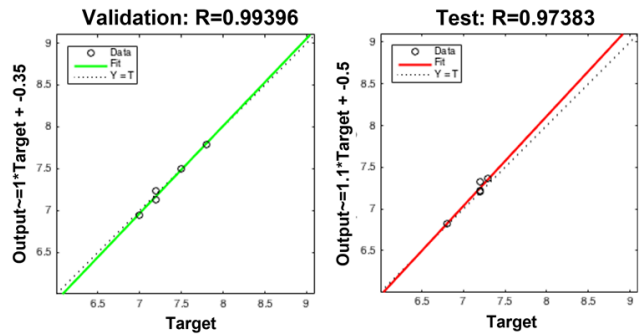

(b)
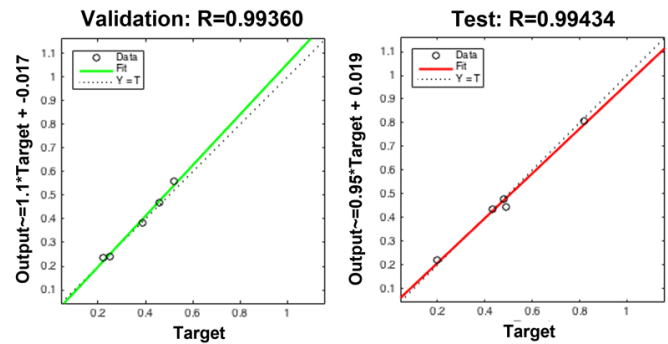

(d)

Figure A4. R value plots for validation and testing phase of the NN-PSO: (a) wet season temperature; (b) wet season $\mathrm{pH}$; (c) wet season EC; (d) wet season TDS.
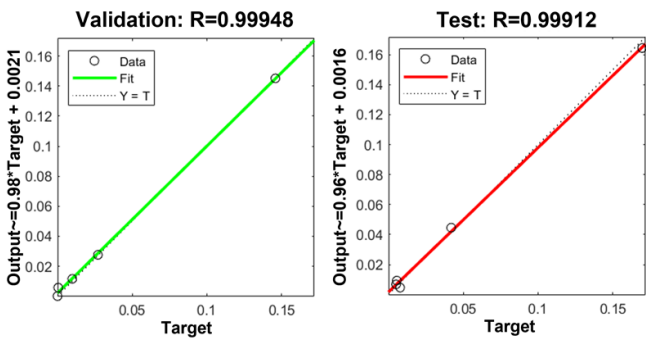

(a)
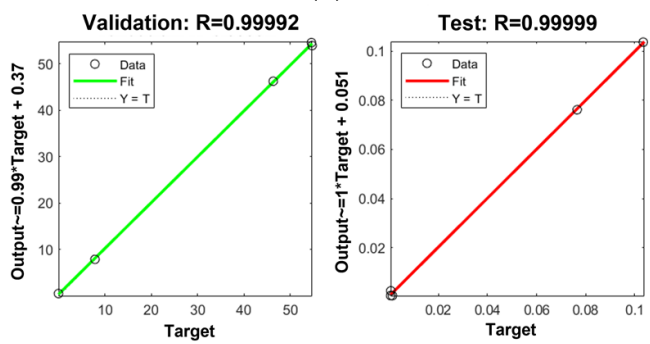

(c)
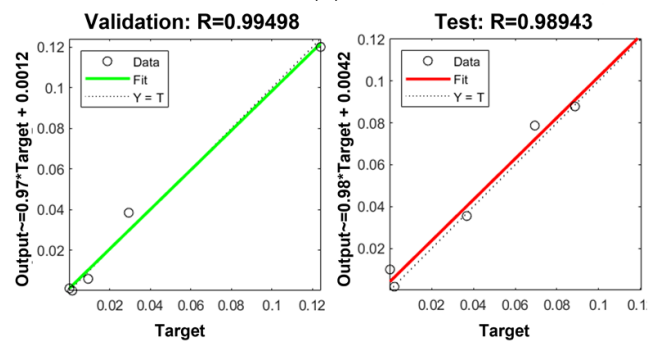

(e)
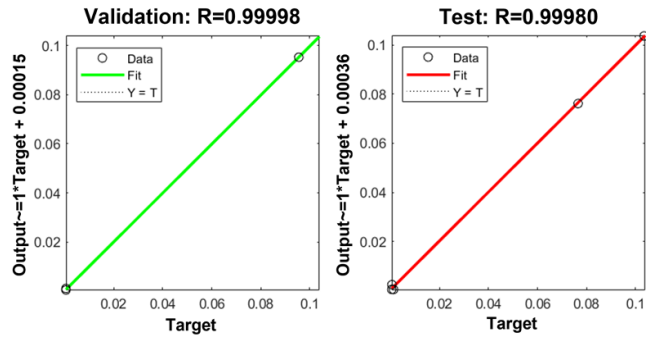

(b)
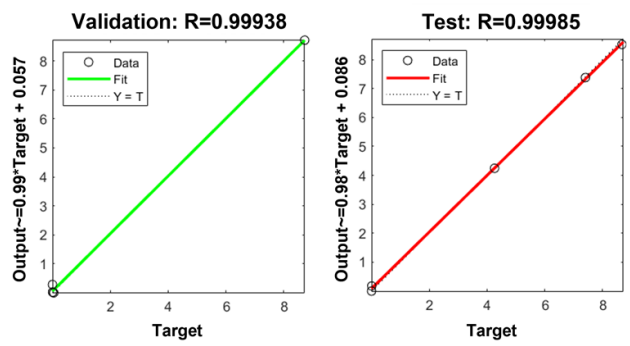

(d)
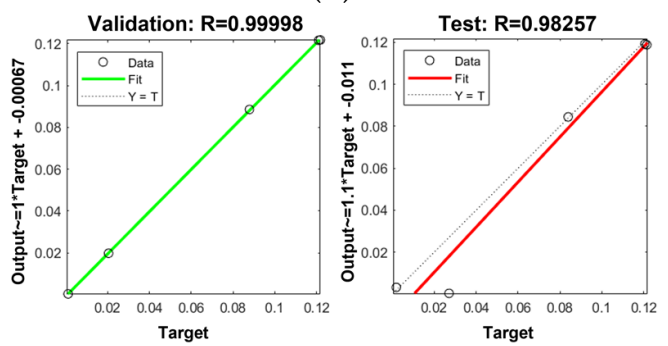

(f)

Figure A5. R value plots for validation and testing phase of the NN-PSO: (a) wet season Cr; (b) wet season $\mathrm{Cd}$; (c) wet season $\mathrm{Fe}$; (d) wet season $\mathrm{Mn}$; (e) wet season $\mathrm{Ni}$; (f) wet season $\mathrm{Pb}$. 


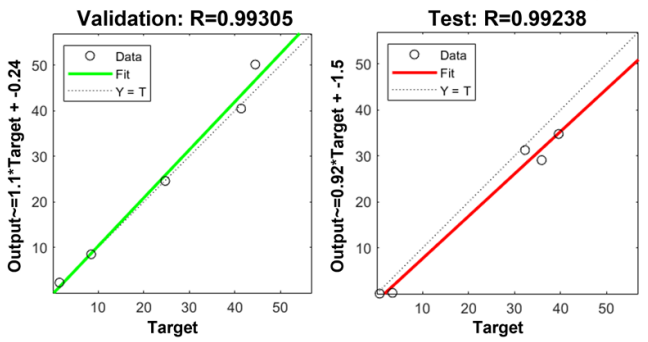

(a)
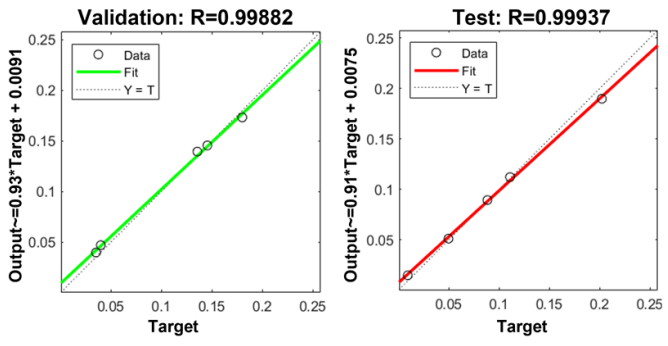

(b)

Figure A6. R value plots for validation and testing phase of the NN-PSO: (a) wet season Zn; (b) wet season $\mathrm{Cu}$.

\section{Appendix B}

Table A1. Performance of methods used to interpolate GW quality parameters during dry season.

\begin{tabular}{|c|c|c|c|c|c|c|c|c|c|c|}
\hline \multirow[t]{2}{*}{ Parameter } & \multirow{2}{*}{$\begin{array}{c}\text { Cross } \\
\text { Validation }\end{array}$} & \multicolumn{4}{|c|}{$\begin{array}{l}\text { Deterministic } \\
\text { Methods }\end{array}$} & \multicolumn{3}{|c|}{$\begin{array}{l}\text { Geostatistical } \\
\text { Methods }\end{array}$} & \multicolumn{2}{|c|}{$\begin{array}{c}\text { Interpolation with } \\
\text { Barriers }\end{array}$} \\
\hline & & IDW & GPI & RBF & LPI & OK & UK & EBK & KS & DK \\
\hline \multirow{2}{*}{ Temp * } & MAE & 0.239 & 0.003 & 0.006 & 0.059 & 0.038 & 0.086 & 0.066 & 0.089 & 0.081 \\
\hline & $\mathrm{R}$ & 0.142 & 0.0003 & 0.082 & 0.092 & 0.055 & 0.071 & 0.004 & 0.183 & 0.004 \\
\hline \multirow{2}{*}{ Temp ** } & MAE & 0.030 & 0.009 & 0.006 & 0.057 & 0.002 & 0.026 & 0.029 & 0.060 & 0.099 \\
\hline & $\mathrm{R}$ & 0.889 & 0.112 & 0.916 & 0.933 & 0.941 & 0.939 & 0.940 & 0.934 & 0.757 \\
\hline \multirow{2}{*}{$\mathrm{pH}^{*}$} & MAE & 0.019 & 0.002 & 0.004 & 0.007 & 0.011 & 0.009 & 0.015 & 0.020 & 0.010 \\
\hline & $\mathrm{R}$ & 0.150 & 0.003 & 0.008 & 0.022 & 0.101 & 0.098 & 0.155 & 0.365 & 0.095 \\
\hline \multirow{2}{*}{$\mathrm{pH}^{* *}$} & MAE & 0.003 & 0.010 & 0.002 & 0.004 & 0.004 & 0.009 & 0.001 & 0.001 & 0.002 \\
\hline & $\mathrm{R}$ & 0.905 & 0.108 & 0.920 & 0.930 & 0.943 & 0.942 & 0.945 & 0.938 & 0.796 \\
\hline \multirow{2}{*}{$\mathrm{EC} *$} & MAE & 0.013 & 0.005 & 0.024 & 0.048 & 0.031 & 0.022 & 0.023 & 0.086 & 0.027 \\
\hline & $\mathrm{R}$ & 0.313 & 0.306 & 0.177 & 0.110 & 0.128 & 0.388 & 0.157 & 0.323 & 0.076 \\
\hline \multirow{2}{*}{$\mathrm{EC}^{* *}$} & MAE & 0.003 & 0.010 & 0.002 & 0.004 & 0.002 & 0.018 & 0.004 & 0.007 & 0.015 \\
\hline & $\mathrm{R}$ & 0.940 & 0.278 & 0.952 & 0.964 & 0.974 & 0.970 & 0.973 & 0.970 & 0.849 \\
\hline \multirow{2}{*}{ TDS * } & MAE & 0.002 & 0.002 & 0.005 & 0.023 & 0.019 & 0.022 & 0.013 & 0.028 & 0.008 \\
\hline & $\mathrm{R}$ & 0.111 & 0.545 & 0.001 & 0.039 & 0.158 & 0.154 & 0.182 & 0.195 & 0.080 \\
\hline \multirow{2}{*}{ TDS ** } & MAE & 0.004 & 0.003 & 0.003 & 0.006 & 0.002 & 0.003 & 0.001 & 0.004 & 0.006 \\
\hline & $\mathrm{R}$ & 0.863 & 0.155 & 0.869 & 0.887 & 0.887 & 0.890 & 0.901 & 0.888 & 0.861 \\
\hline \multirow{2}{*}{$\mathrm{Cr}^{*}$} & MAE & 0.0007 & 0.00008 & 0.0001 & 0.0007 & 0.0006 & 0.008 & 0.00007 & 0.0003 & 0.002 \\
\hline & $\mathrm{R}$ & 0.700 & 0.605 & 0.704 & 0.679 & 0.716 & 0.510 & 0.683 & 0.615 & 0.681 \\
\hline \multirow{2}{*}{$\mathrm{Cr}{ }^{* *}$} & MAE & 0.0002 & 0.0002 & 0.00008 & 0.0001 & 0.0001 & 0.002 & 0.00007 & 0.00007 & 0.0002 \\
\hline & $\mathrm{R}$ & 0.966 & 0.679 & 0.968 & 0.970 & 0.967 & 0.957 & 0.971 & 0.970 & 0.946 \\
\hline \multirow{2}{*}{$\mathrm{Cd}^{*}$} & MAE & 0.0006 & 0.00002 & 0.0002 & 0.0002 & 0.0005 & 0.002 & 0.0001 & 0.0003 & 0.003 \\
\hline & $\mathrm{R}$ & 0.822 & 0.705 & 0.819 & 0.738 & 0.832 & 0.552 & 0.786 & 0.738 & 0.713 \\
\hline \multirow{2}{*}{$C d^{* *}$} & MAE & 0.0001 & $\begin{array}{l}9.1 \times \\
10^{-5}\end{array}$ & 0.0002 & $\begin{array}{c}8.4 \times \\
10^{-5}\end{array}$ & 0.00004 & 0.008 & $\begin{array}{l}6.5 \times \\
10^{-5}\end{array}$ & $\begin{array}{l}1.5 \times \\
10^{-5}\end{array}$ & 0.0001 \\
\hline & $\mathrm{R}$ & 0.965 & 0.699 & 0.980 & 0.977 & 0.979 & 0.937 & 0.981 & 0.979 & 0.898 \\
\hline \multirow{2}{*}{$\mathrm{Fe}^{*}$} & MAE & 0.269 & 0.020 & 0.090 & 0.283 & 0.375 & 0.167 & 0.038 & 0.120 & 0.078 \\
\hline & $\mathrm{R}$ & 0.077 & 0.169 & 0.134 & 0.089 & 0.095 & 0.039 & 0.160 & 0.010 & 0.160 \\
\hline \multirow{2}{*}{$\mathrm{Fe}^{* *}$} & MAE & 0.187 & 0.500 & 0.068 & 0.135 & 0.046 & 0.540 & 0.045 & 0.101 & 0.100 \\
\hline & $\mathrm{R}$ & 0.906 & 0.258 & 0.906 & 0.920 & 0.932 & 0.739 & 0.940 & 0.920 & 0.742 \\
\hline \multirow{2}{*}{$\mathrm{Mn}^{*}$} & MAE & 0.105 & 0.006 & 0.050 & 0.011 & 0.029 & 0.086 & 0.022 & 0.040 & 0.031 \\
\hline & $\mathrm{R}$ & 0.127 & 0.199 & 0.041 & 0.195 & 0.185 & 0.125 & 0.228 & 0.155 & 0.294 \\
\hline \multirow{2}{*}{$\mathrm{Mn}^{* *}$} & MAE & 0.027 & 0.006 & 0.006 & 0.007 & 0.005 & 0.841 & 0.007 & 0.008 & 0.019 \\
\hline & $\mathrm{R}$ & 0.841 & 0.089 & 0.857 & 0.879 & 0.922 & 0.815 & 0.908 & 0.889 & 0.645 \\
\hline \multirow{2}{*}{$\mathrm{Ni}^{*}$} & MAE & 0.0007 & 0.0003 & 0.0004 & 0.0003 & 0.0006 & 0.002 & 0.0006 & 0.0004 & 0.004 \\
\hline & $\mathrm{R}$ & 0.817 & 0.707 & 0.820 & 0.737 & 0.829 & 0.570 & 0.780 & 0.730 & 0.714 \\
\hline \multirow{2}{*}{$\mathrm{Ni}{ }^{* *}$} & MAE & 0.0003 & 0.004 & 0.0002 & 0.0003 & 0.0004 & 0.007 & 0.0003 & 0.0002 & 0.0005 \\
\hline & $\mathrm{R}$ & 0.963 & 0.666 & 0.991 & 0.979 & 0.987 & 0.982 & 0.986 & 0.978 & 0.883 \\
\hline \multirow{2}{*}{$\mathrm{Pb}$ * } & MAE & 0.0008 & 0.0005 & 0.0002 & 0.0009 & 0.0003 & 0.0010 & 0.0004 & 0.0003 & 0.003 \\
\hline & $\mathrm{R}$ & 0.778 & 0.673 & 0.774 & 0.710 & 0.813 & 0.632 & 0.744 & 0.702 & 0.691 \\
\hline
\end{tabular}


Table A1. Cont.

\begin{tabular}{|c|c|c|c|c|c|c|c|c|c|c|}
\hline \multirow[t]{2}{*}{ Parameter } & \multirow{2}{*}{$\begin{array}{c}\text { Cross } \\
\text { Validation }\end{array}$} & \multicolumn{4}{|c|}{$\begin{array}{l}\text { Deterministic } \\
\text { Methods }\end{array}$} & \multicolumn{3}{|c|}{$\begin{array}{l}\text { Geostatistical } \\
\text { Methods }\end{array}$} & \multicolumn{2}{|c|}{$\begin{array}{c}\text { Interpolation with } \\
\text { Barriers }\end{array}$} \\
\hline & & IDW & GPI & RBF & LPI & OK & UK & EBK & KS & DK \\
\hline \multirow{2}{*}{$\mathrm{Pb}^{* *}$} & MAE & 0.0005 & 0.0001 & 0.0006 & 0.0003 & 0.0001 & 0.006 & 0.0001 & 0.0003 & 0.0008 \\
\hline & $\mathrm{R}$ & 0.971 & 0.740 & 0.982 & 0.985 & 0.985 & 0.976 & 0.989 & 0.986 & 0.906 \\
\hline \multirow{2}{*}{$\mathrm{Zn}$ * } & MAE & 0.130 & 0.054 & 0.310 & 0.149 & 0.993 & 0.121 & 0.183 & 0.669 & 0.111 \\
\hline & $\mathrm{R}$ & 0.177 & 0.325 & 0.247 & 0.067 & 0.082 & 0.187 & 0.395 & 0.125 & 0.428 \\
\hline \multirow{2}{*}{$\mathrm{Zn} * *$} & MAE & 0.449 & 0.018 & 0.157 & 0.350 & 0.073 & 0.074 & 0.017 & 0.255 & 0.381 \\
\hline & $\mathrm{R}$ & 0.908 & 0.363 & 0.927 & 0.938 & 0.946 & 0.879 & 0.951 & 0.926 & 0.739 \\
\hline \multirow{2}{*}{$\mathrm{Cu}^{*}$} & MAE & 0.0003 & 0.0004 & 0.003 & 0.0006 & 0.0005 & 0.073 & 0.002 & 0.0005 & 0.003 \\
\hline & $\mathrm{R}$ & 0.223 & 0.246 & 0.212 & 0.193 & 0.251 & 0.335 & 0.189 & 0.336 & 0.039 \\
\hline \multirow{2}{*}{$\mathrm{Cu}^{* *}$} & MAE & 0.002 & 0.001 & 0.0008 & 0.0008 & 0.0005 & 0.007 & 0.0002 & 0.0004 & 0.003 \\
\hline & $\mathrm{R}$ & 0.941 & 0.347 & 0.953 & 0.966 & 0.972 & 0.961 & 0.974 & 0.965 & 0.850 \\
\hline
\end{tabular}

** Neuro-particle swarm optimization informed; * Without neuro-particle swarm optimization.

Table A2. Performance of methods used to interpolate GW quality parameters during wet season.

\begin{tabular}{|c|c|c|c|c|c|c|c|c|c|c|}
\hline \multirow[t]{2}{*}{ Parameter } & \multirow{2}{*}{$\begin{array}{c}\text { Cross } \\
\text { Validation }\end{array}$} & \multicolumn{4}{|c|}{$\begin{array}{c}\text { Deterministic } \\
\text { Methods }\end{array}$} & \multicolumn{3}{|c|}{$\begin{array}{c}\text { Geostatistical } \\
\text { Methods }\end{array}$} & \multicolumn{2}{|c|}{$\begin{array}{l}\text { Interpolation } \\
\text { with Barriers }\end{array}$} \\
\hline & & IDW & GPI & RBF & LPI & OK & UK & EBK & KS & DK \\
\hline \multirow{2}{*}{ Temp * } & MAE & 0.166 & 0.011 & 0.037 & 0.067 & 0.060 & 0.035 & 0.146 & 0.333 & 0.084 \\
\hline & $\mathrm{R}$ & 0.050 & 0.039 & 0.053 & 0.083 & 0.111 & 0.118 & 0.107 & 0.118 & 0.236 \\
\hline \multirow{2}{*}{ Temp ** } & MAE & 0.060 & 0.010 & 0.026 & 0.046 & 0.004 & 0.010 & 0.005 & 0.019 & 0.088 \\
\hline & $\mathrm{R}$ & 0.890 & 0.311 & 0.923 & 0.902 & 0.925 & 0.916 & 0.922 & 0.911 & 0.780 \\
\hline \multirow{2}{*}{$\mathrm{pH}^{*}$} & MAE & 0.019 & 0.002 & 0.003 & 0.032 & 0.030 & 0.023 & 0.004 & 0.065 & 0.007 \\
\hline & $\mathrm{R}$ & 0.359 & 0.239 & 0.321 & 0.107 & 0.242 & 0.264 & 0.033 & 0.298 & 0.150 \\
\hline \multirow{2}{*}{$\mathrm{pH}^{* *}$} & MAE & 0.011 & 0.0003 & 0.005 & 0.004 & 0.0003 & 0.0004 & 0.004 & 0.008 & 0.010 \\
\hline & $\mathrm{R}$ & 0.916 & 0.046 & 0.959 & 0.960 & 0.976 & 0.975 & 0.974 & 0.957 & 0.762 \\
\hline \multirow{2}{*}{$\mathrm{EC} *$} & MAE & 0.007 & 0.001 & 0.003 & 0.032 & 0.002 & 0.026 & 0.003 & 0.077 & 0.007 \\
\hline & $\mathrm{R}$ & 0.030 & 0.224 & 0.026 & 0.008 & 0.127 & 0.104 & 0.048 & 0.030 & 0.073 \\
\hline \multirow{2}{*}{$\mathrm{EC}^{* *}$} & MAE & 0.009 & 0.0005 & 0.002 & 0.002 & 0.0004 & 0.012 & 0.0002 & 0.005 & 0.0006 \\
\hline & $\mathrm{R}$ & 0.905 & 0.309 & 0.934 & 0.945 & 0.955 & 0.945 & 0.962 & 0.953 & 0.766 \\
\hline \multirow{2}{*}{ TDS * } & MAE & 0.013 & 0.003 & 0.011 & 0.019 & 0.015 & 0.011 & 0.001 & 0.017 & 0.015 \\
\hline & $\mathrm{R}$ & 0.003 & 0.284 & 0.083 & 0.212 & 0.189 & 0.057 & 0.167 & 0.106 & 0.020 \\
\hline \multirow{2}{*}{ TDS ** } & MAE & 0.005 & 0.020 & 0.002 & 0.002 & 0.002 & 0.014 & 0.001 & 0.001 & 0.007 \\
\hline & $\mathrm{R}$ & 0.928 & 0.254 & 0.944 & 0.954 & 0.964 & 0.939 & 0.964 & 0.951 & 0.830 \\
\hline \multirow{2}{*}{$\mathrm{Cr}^{*}$} & MAE & 0.0008 & 0.0003 & 0.001 & 0.001 & 0.0006 & 0.051 & 0.003 & 0.007 & 0.0006 \\
\hline & $\mathrm{R}$ & 0.206 & 0.097 & 0.007 & 0.057 & 0.149 & 0.168 & 0.128 & 0.015 & 0.041 \\
\hline \multirow{2}{*}{$\mathrm{Cr}^{* *}$} & MAE & 0.0001 & 0.001 & 0.0005 & 0.0005 & 0.0001 & 0.174 & 0.0004 & 0.0002 & 0.0003 \\
\hline & $\mathrm{R}$ & 0.912 & 0.138 & 0.938 & 0.932 & 0.963 & 0.856 & 0.960 & 0.944 & 0.637 \\
\hline \multirow{2}{*}{$\mathrm{Cd}^{*}$} & MAE & 0.004 & 0.0002 & 0.0007 & 0.005 & 0.0005 & 0.022 & 0.003 & 0.007 & 0.0006 \\
\hline & $\mathrm{R}$ & 0.304 & 0.291 & 0.570 & 0.599 & 0.573 & 0.784 & 0.128 & 0.015 & 0.041 \\
\hline \multirow{2}{*}{$\mathrm{Cd}^{* *}$} & MAE & 0.0002 & 0.0003 & 0.0002 & 0.0002 & 0.0001 & 0.011 & 0.0001 & 0.0005 & 0.0002 \\
\hline & $\mathrm{R}$ & 0.920 & 0.218 & 0.949 & 0.936 & 0.961 & 0.836 & 0.957 & 0.939 & 0.747 \\
\hline \multirow{2}{*}{$\mathrm{Fe}^{*}$} & MAE & 0.373 & 0.038 & 0.823 & 0.612 & 0.198 & 0.197 & 0.328 & 0.969 & 0.661 \\
\hline & $\mathrm{R}$ & 0.386 & 0.114 & 0.181 & 0.129 & 0.272 & 0.271 & 0.302 & 0.064 & 0.136 \\
\hline \multirow{2}{*}{$\mathrm{Fe}^{* *}$} & MAE & 0.064 & 0.002 & 0.030 & 0.101 & 0.025 & 0.055 & 0.055 & 0.107 & 0.068 \\
\hline & $\mathrm{R}$ & 0.924 & 0.376 & 0.949 & 0.950 & 0.942 & 0.705 & 0.952 & 0.931 & 0.745 \\
\hline \multirow{2}{*}{$\mathrm{Mn}$ * } & MAE & 0.545 & 0.007 & 0.132 & 0.236 & 0.239 & 0.712 & 0.029 & 0.375 & 0.090 \\
\hline & $\mathrm{R}$ & 0.169 & 0.477 & 0.326 & 0.434 & 0.326 & 0.641 & 0.374 & 0.342 & 0.322 \\
\hline \multirow{2}{*}{$\mathrm{Mn}^{* *}$} & MAE & 0.014 & 0.003 & 0.002 & 0.051 & 0.005 & 0.264 & 0.005 & 0.042 & 0.071 \\
\hline & $\mathrm{R}$ & 0.878 & 0.244 & 0.926 & 0.920 & 0.930 & 0.786 & 0.935 & 0.927 & 0.715 \\
\hline \multirow{2}{*}{$\mathrm{Ni}^{*}$} & MAE & 0.002 & 0.0002 & 0.0001 & 0.003 & 0.00002 & 0.069 & 0.0009 & 0.0005 & 0.0009 \\
\hline & $\mathrm{R}$ & 0.519 & 0.662 & 0.622 & 0.488 & 0.580 & 0.497 & 0.531 & 0.468 & 0.125 \\
\hline \multirow{2}{*}{$\mathrm{Ni}^{* *}$} & MAE & 0.0005 & 0.00004 & 0.0001 & 0.0005 & 0.00009 & 0.0105 & 0.00005 & 0.0003 & 0.0006 \\
\hline & $\mathrm{R}$ & 0.912 & 0.252 & 0.945 & 0.938 & 0.944 & 0.754 & 0.954 & 0.941 & 0.750 \\
\hline
\end{tabular}


Table A2. Cont.

\begin{tabular}{|c|c|c|c|c|c|c|c|c|c|c|}
\hline \multirow[t]{2}{*}{ Parameter } & \multirow{2}{*}{$\begin{array}{c}\text { Cross } \\
\text { Validation }\end{array}$} & \multicolumn{4}{|c|}{$\begin{array}{l}\text { Deterministic } \\
\text { Methods }\end{array}$} & \multicolumn{3}{|c|}{$\begin{array}{l}\text { Geostatistical } \\
\text { Methods }\end{array}$} & \multicolumn{2}{|c|}{$\begin{array}{l}\text { Interpolation } \\
\text { with Barriers }\end{array}$} \\
\hline & & IDW & GPI & RBF & LPI & OK & UK & EBK & KS & DK \\
\hline \multirow{2}{*}{$\mathrm{Pb}$ * } & MAE & 0.006 & 0.0003 & 0.0006 & 0.003 & 0.006 & 0.029 & 0.0007 & 0.003 & 0.0003 \\
\hline & $\mathrm{R}$ & 0.068 & 0.285 & 0.157 & 0.314 & 0.210 & 0.363 & 0.337 & 0.284 & 0.378 \\
\hline \multirow{2}{*}{$\mathrm{Pb} * *$} & MAE & 0.0004 & 0.002 & 0.0003 & 0.0003 & 0.0003 & 0.156 & 0.0002 & 0.0003 & 0.0006 \\
\hline & $\mathrm{R}$ & 0.862 & 0.193 & 0.888 & 0.863 & 0.892 & 0.733 & 0.900 & 0.869 & 0.681 \\
\hline \multirow{2}{*}{$\mathrm{Zn}$ * } & MAE & 0.263 & 0.060 & 0.810 & 0.941 & 0.204 & 0.389 & 0.158 & 0.167 & 0.018 \\
\hline & $\mathrm{R}$ & 0.172 & 0.727 & 0.162 & 0.154 & 0.358 & 0.728 & 0.778 & 0.213 & 0.594 \\
\hline \multirow{2}{*}{$\mathrm{Zn}{ }^{* *}$} & MAE & 0.037 & 0.015 & 0.019 & 0.033 & 0.023 & 0.399 & 0.063 & 0.098 & 0.023 \\
\hline & $\mathrm{R}$ & 0.905 & 0.038 & 0.956 & 0.898 & 0.949 & 0.847 & 0.937 & 0.904 & 0.721 \\
\hline \multirow{2}{*}{$\mathrm{Cu}^{*}$} & MAE & 0.009 & 0.0009 & 0.004 & 0.003 & 0.004 & 0.150 & 0.007 & 0.007 & 0.006 \\
\hline & $\mathrm{R}$ & 0.687 & 0.072 & 0.624 & 0.169 & 0.259 & 0.465 & 0.388 & 0.233 & 0.340 \\
\hline \multirow{2}{*}{$\mathrm{Cu}{ }^{* *}$} & MAE & 0.0009 & 0.0005 & 0.0006 & 0.0004 & 0.0002 & 0.226 & 0.0006 & 0.002 & 0.0004 \\
\hline & $\mathrm{R}$ & 0.917 & 0.049 & 0.915 & 0.886 & 0.926 & 0.813 & 0.924 & 0.863 & 0.722 \\
\hline
\end{tabular}

** Neuro-particle swarm optimization informed; * Without neuro-particle swarm optimization.

\section{Appendix C}

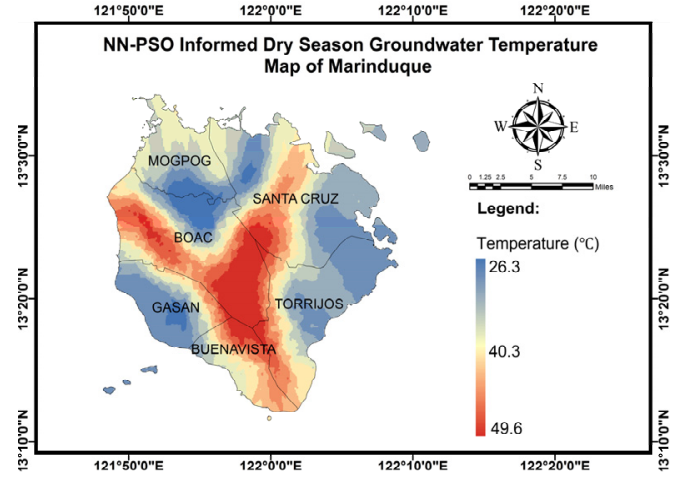

(a)

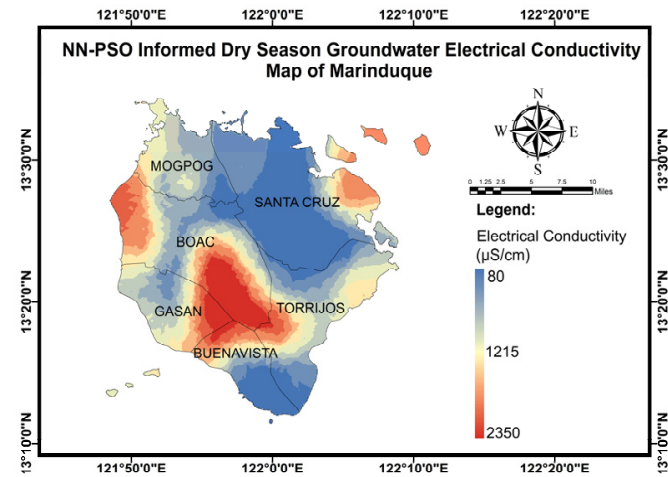

(c)

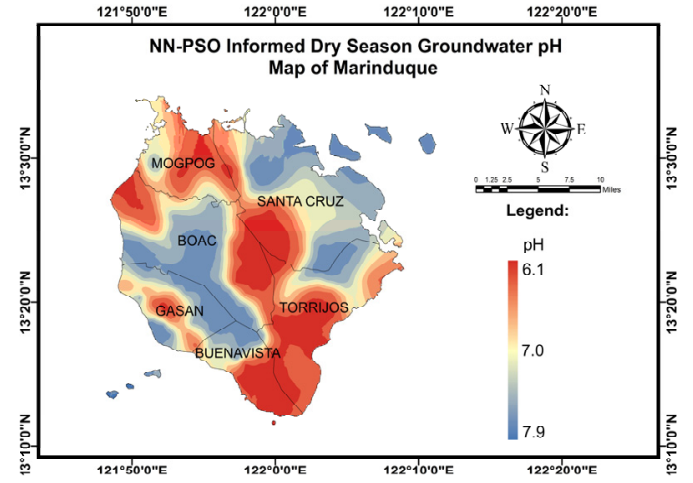

(b)

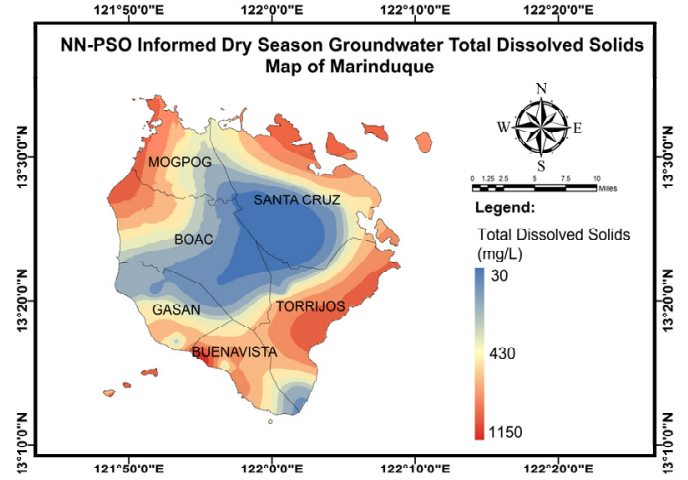

(d)

Figure A7. NN-PSO informed maps of the GW physicochemical characteristics during dry season: (a) temperature; (b) pH; (c) EC; (d) TDS. 


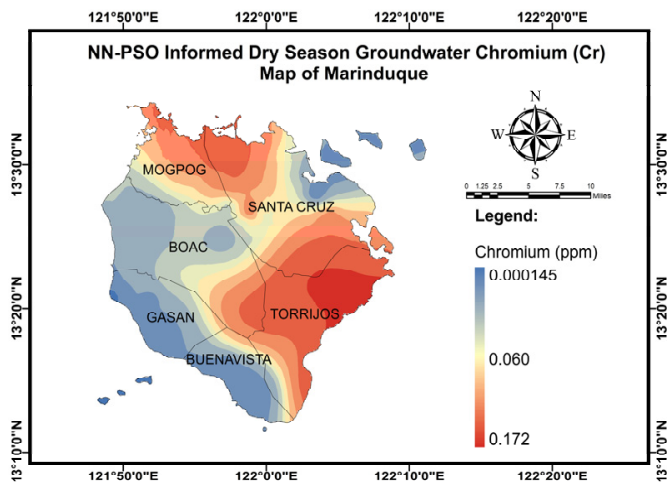

(a)

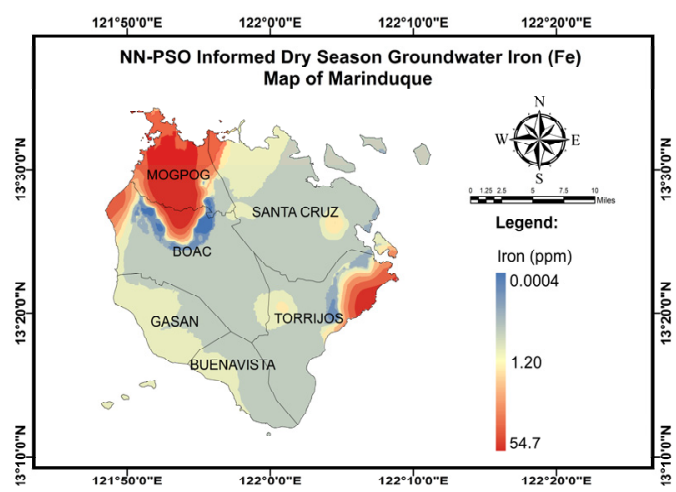

(c)

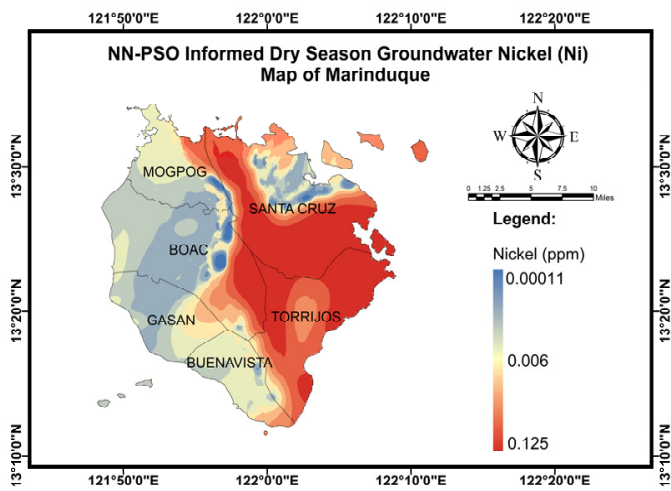

(e)

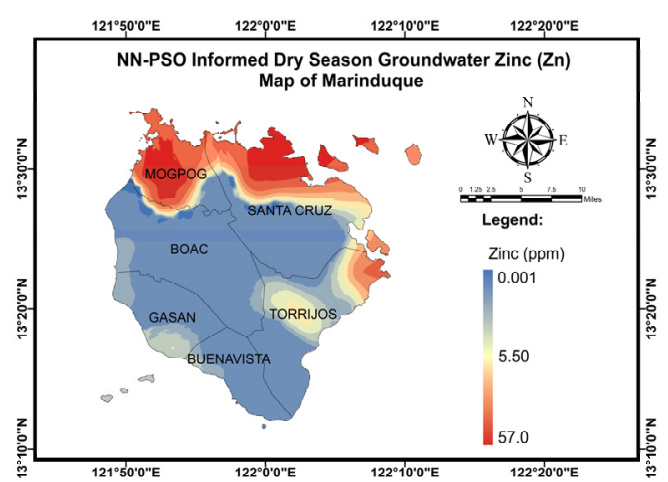

(g)

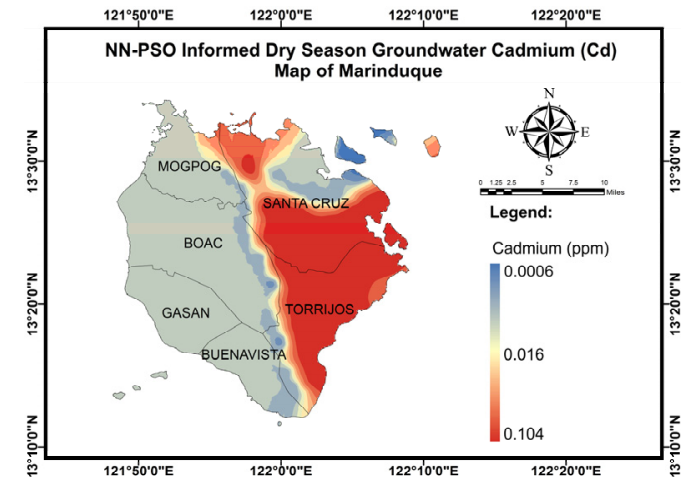

(b)

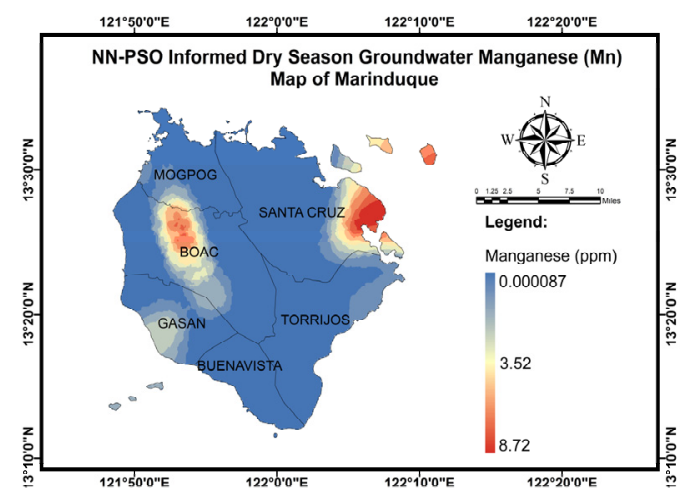

(d)

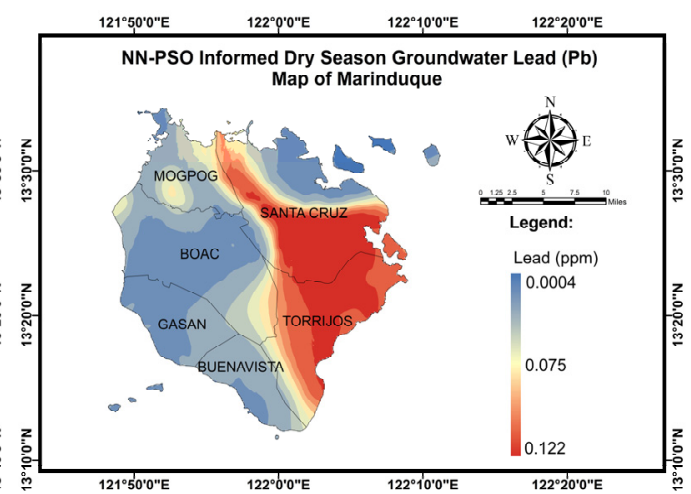

(f)

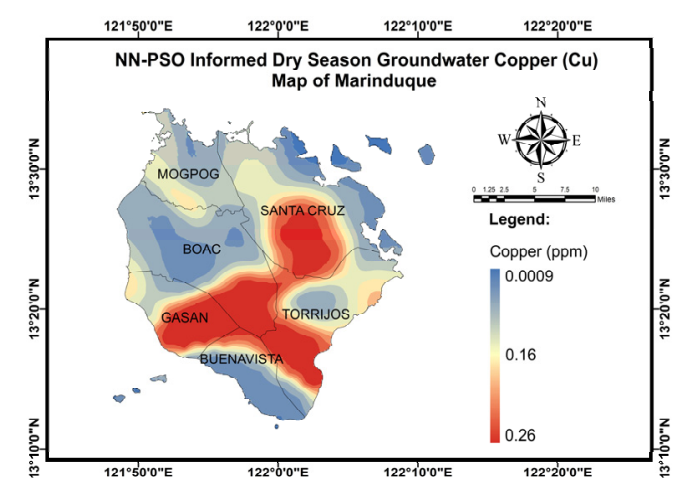

(h)

Figure A8. NN-PSO informed maps of the GW heavy metal concentration during dry season: (a) Cr; (b) Cd; (c) Fe; (d) Mn; (e) $\mathrm{Ni}$; (f) $\mathrm{Pb}$; (g) $\mathrm{Zn}$; (h) Cu. 


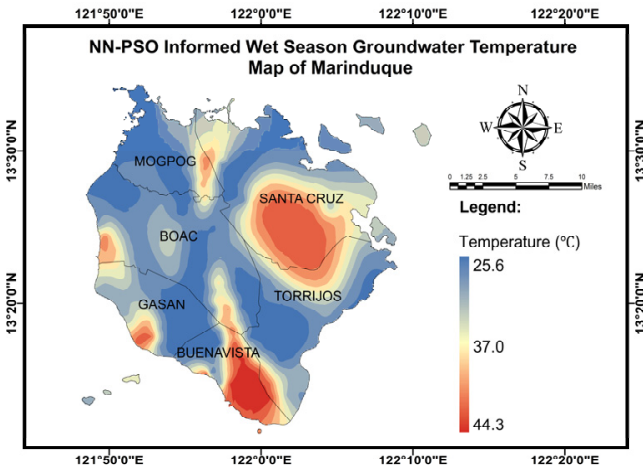

(a)

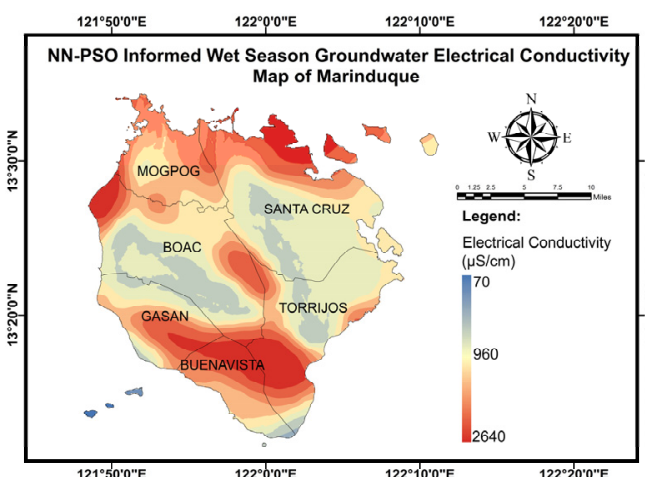

(c)

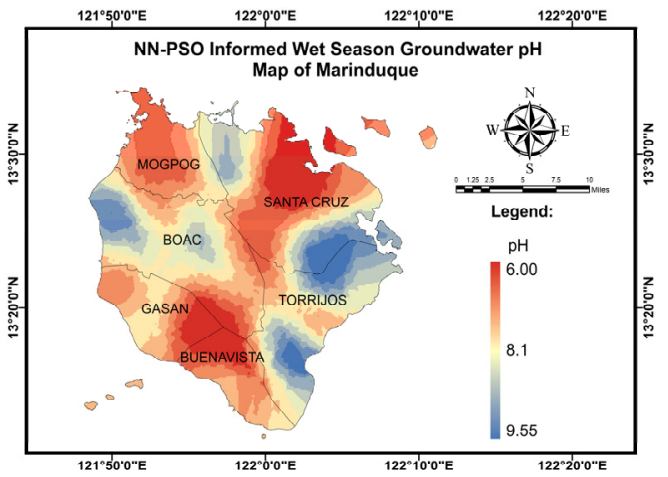

(b)

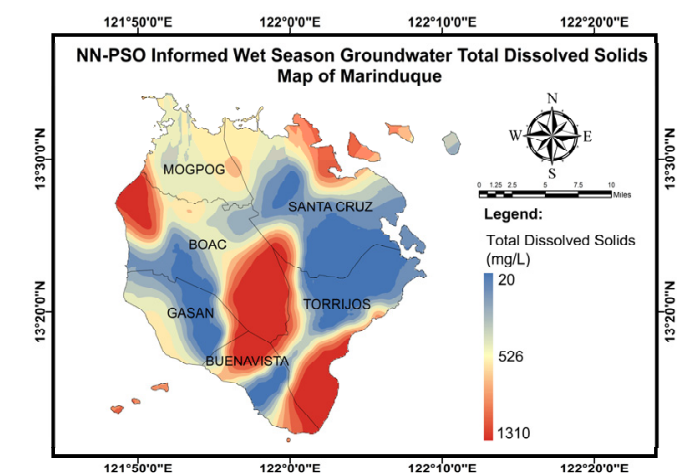

(d)

Figure A9. NN-PSO informed maps of the GW physicochemical characteristics during wet season: (a) temperature; (b) pH; (c) EC; (d) TDS.

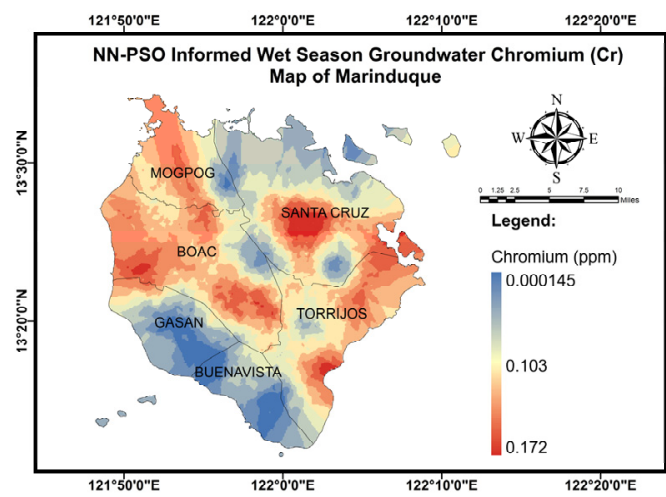

(a)

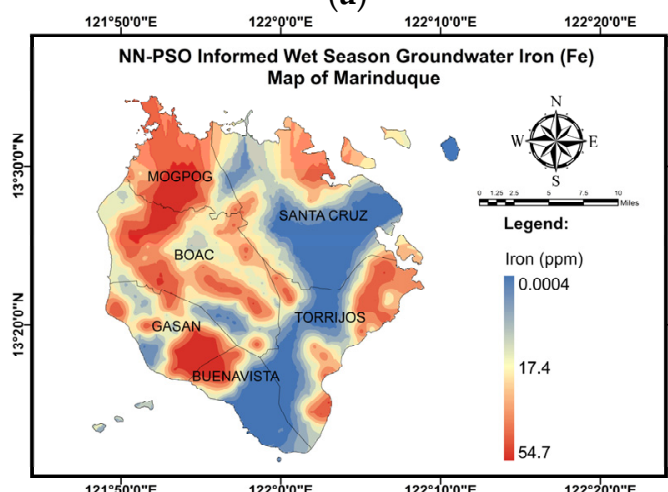

(c)

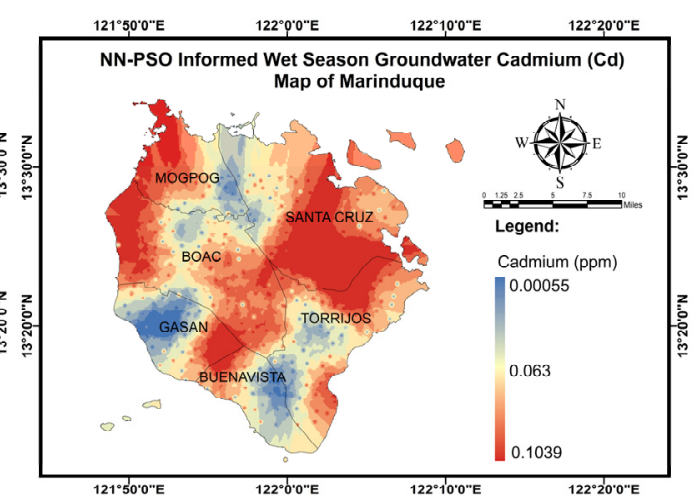

(b)

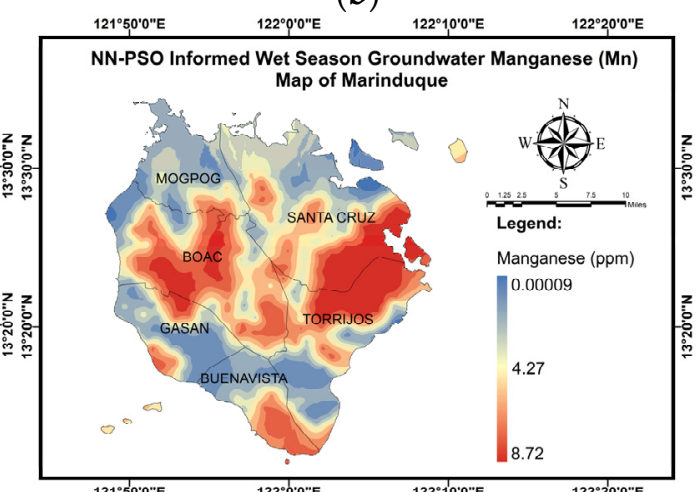

(d)

Figure A10. NN-PSO informed maps of the GW HM concentration during wet season: (a) Cr; (b) Cd; (c) Fe; (d) Mn. 


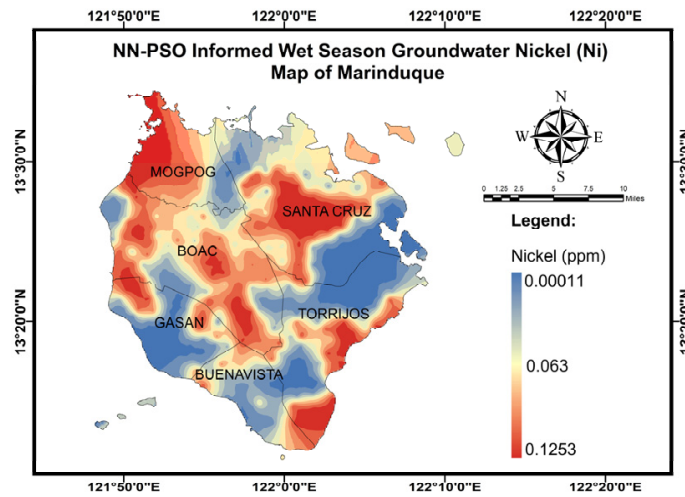

(a)

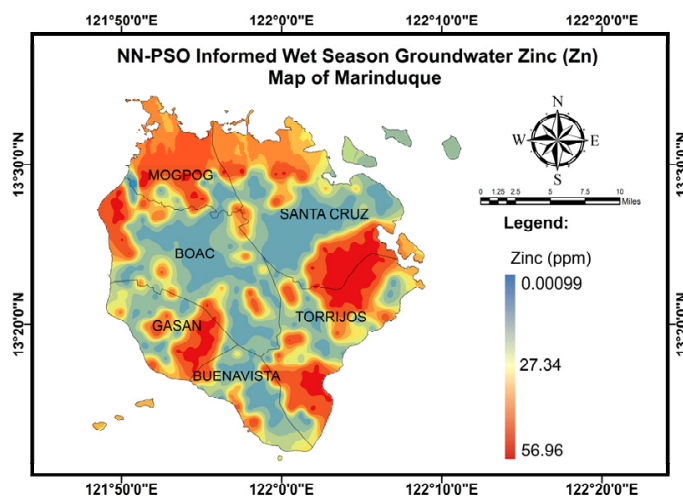

(c)

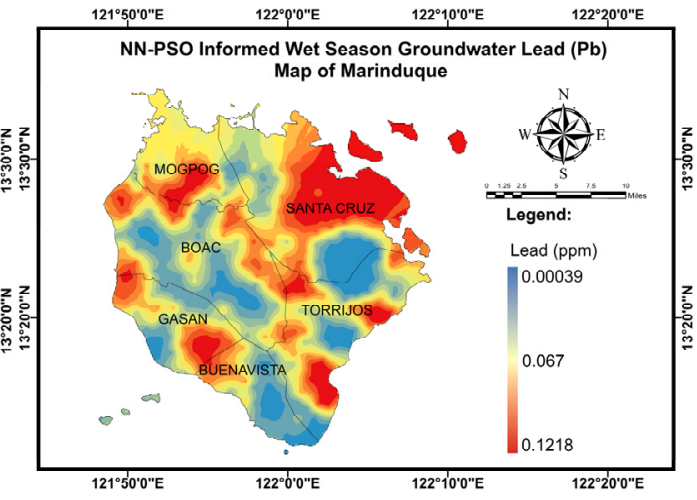

(b)

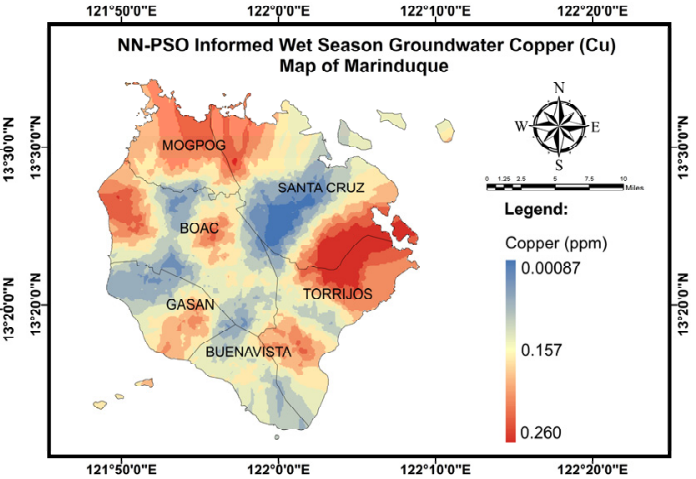

(d)

Figure A11. NN-PSO informed maps of the GW HM concentration during wet season: (a) Ni; (b) $\mathrm{Pb}$; (c) Zn; (d) Cu.

\section{References}

1. Flores, H.; Lorenz, S.; Jackisch, R.; Tusa, L.; Contreras, I.C.; Zimmermann, R.; Gloaguen, R. UAS-Based Hyperspectral Environmental Monitoring of Acid Mine Drainage Affected Waters. Minerals 2021, 11, 182. [CrossRef]

2. Park, I.; Tabelin, C.B.; Jeon, S.; Li, X.; Seno, K.; Ito, M.; Hiroyoshi, N. A review of recent strategies for acid mine drainage prevention and mine tailings recycling. Chemosphere 2019, 219, 588-606. [CrossRef]

3. Naidu, G.; Ryu, S.; Thiruvenkatachari, R.; Choi, Y.; Jeong, S.; Vigneswaran, S. A critical review on remediation, reuse, and resource recovery from acid mine drainage. Environ. Pollut. 2019, 247, 1110-1124. [CrossRef] [PubMed]

4. Kefeni, K.K.; Msagati, T.A.; Mamba, B.B. Acid mine drainage: Prevention, treatment options, and resource recovery: A review. J. Clean. Prod. 2017, 151, 475-493. [CrossRef]

5. Simate, G.S.; Ndlovu, S. Acid mine drainage: Challenges and opportunities. J. Environ. Chem. Eng. 2014, 2, 1785-1803. [CrossRef]

6. Wei, T.T.; Yu, Y.; Hu, Z.Q.; Cao, Y.B.; Gao, Y.; Yang, Y.Q.; Wang, X.J.; Wang, P.J. Research progress of acid mine drainage treatment technology in China. In Applied Mechanics and Materials; Trans Tech Publications Ltd.: Bäch SZ, Switzerland, 2013; Volume 409, pp. 214-220.

7. Senoro, D.B.; Bonifacio, P.B.; Mascareñas, D.R.; Tabelin, C.B.; Ney, F.P.; Lamac, M.R.L.; Tan, F.J. Spatial distribution of agricultural yields with elevated metal concentration of the island exposed to acid mine drainage. J. Degrad. Min. Lands Manag. 2020, 8 , 2551-2558. [CrossRef]

8. Balci, N.; Demirel, C. Prediction of acid mine drainage (AMD) and metal release sources at the Küre Copper Mine Site, Kastamonu, NW Turkey. Mine Water Environ. 2018, 37, 56-74. [CrossRef]

9. Chamorro, S.; Barata, C.; Piña, B.; Casado, M.; Schwarz, A.; Sáez, K.; Vidal, G. Toxicological analysis of acid mine drainage by water quality and land use bioassays. Mine Water Environ. 2018, 37, 88-97. [CrossRef]

10. Balistrieri, L.S.; Seal, R.R., II; Piatak, N.M.; Paul, B. Assessing the concentration, speciation, and toxicity of dissolved metals during mixing of acid-mine drainage and ambient river water downstream of the Elizabeth Copper Mine, Vermont, USA. Appl. Geochem. 2007, 22, 930-952. [CrossRef]

11. Henri, A.J.; Wepener, V.; Ferreira, M.; Malherbe, W.; Van Vuren, J.H. The effect of acid mine drainage on the hatching success of branchiopod egg banks from endorheic wetlands in South Africa. Hydrobiologia 2014, 738, 35-48. [CrossRef]

12. Vicente-Beckett, V.A.; Taylor McCauley, G.J.; Duivenvoorden, L.J. Metal speciation in sediments and soils associated with acid-mine drainage in Mount Morgan (Queensland, Australia). J. Environ. Sci. Health A 2016, 51, 121-134. [CrossRef] 
13. Leung, A.M.R. Urgent Environmental Health Issues in the Philippines: Overview and Case Studies. In Proceedings of the Korean Environmental Health Society Conference; Korean Society of Environmental Health: Seoul, Korea, 2006; pp. 147-158.

14. Khan, A.M.; Ganai, S.A. Removal and recovery of heavy metal ions using natural adsorbents. In Modern Age Waste Water Problems; Springer: Cham, Switzerland, 2020; pp. 251-260.

15. Unsal, V.; Dalkıran, T.; Çiçek, M.; Kölükçü, E. The role of natural antioxidants against reactive oxygen species produced by cadmium toxicity: A review. Adv. Pharm. Bull. 2020, 10, 184. [CrossRef] [PubMed]

16. Jaishankar, M.; Tseten, T.; Anbalagan, N.; Mathew, B.B.; Beeregowda, K.N. Toxicity, mechanism and health effects of some heavy metals. Interdiscip. Toxicol. 2014, 7, 60. [CrossRef] [PubMed]

17. Hashem, M.A.; Nur-A-Tomal, M.S.; Mondal, N.R.; Rahman, M.A. Hair burning and liming in tanneries is a source of pollution by arsenic, lead, zinc, manganese and iron. Environ. Chem. Lett. 2017, 15, 501-506. [CrossRef]

18. Buxton, S.; Garman, E.; Heim, K.E.; Lyons-Darden, T.; Schlekat, C.E.; Taylor, M.D.; Oller, A.R. Concise review of nickel human health toxicology and ecotoxicology. Inorganics 2019, 7, 89. [CrossRef]

19. Boskabady, M.; Marefati, N.; Farkhondeh, T.; Shakeri, F.; Farshbaf, A.; Boskabady, M.H. The effect of environmental lead exposure on human health and the contribution of inflammatory mechanisms, a review. Environ. Int. 2018, 120, 404-420. [CrossRef]

20. Zatta, P.; Lucchini, R.; van Rensburg, S.J.; Taylor, A. The role of metals in neurodegenerative processes: Aluminum, manganese, and zinc. Brain Res. Bull. 2003, 62, 15-28. [CrossRef]

21. Gaetke, L.M.; Chow, C.K. Copper toxicity, oxidative stress, and antioxidant nutrients. Toxicology 2003, 189, 147-163. [CrossRef]

22. Li, J.; Heap, A.D. Spatial interpolation methods applied in the environmental sciences: A review. Environ. Model. Softw. 2014, 53, 173-189. [CrossRef]

23. Li, J.; Heap, A.D.; Potter, A.; Huang, Z.; Daniell, J.J. Can we improve the spatial predictions of seabed sediments? A case study of spatial interpolation of mud content across the southwest Australian margin. Cont. Shelf Res. 2011, 31, 1365-1376. [CrossRef]

24. Chen, H.; Fan, L.; Wu, W.; Liu, H.B. Comparison of spatial interpolation methods for soil moisture and its application for monitoring drought. Environ. Monit. Assess. 2017, 189, 1-13. [CrossRef]

25. Requia, W.J.; Coull, B.A.; Koutrakis, P. Evaluation of predictive capabilities of ordinary geostatistical interpolation, hybrid interpolation, and machine learning methods for estimating PM2. 5 constituents over space. Environ. Res. 2019, 175, 421-433. [CrossRef]

26. Reinhardt, K.; Samimi, C. Comparison of different wind data interpolation methods for a region with complex terrain in Central Asia. Clim. Dyn. 2018, 51, 3635-3652. [CrossRef]

27. Gumus, K.; Sen, A. Comparison of Spatial Interpolation Methods and Multi-Layer Neural Networks Different Point Distributions on a Digital Elevation Model. Geod. Vestn. 2013, 57, 523-543. [CrossRef]

28. Bhunia, G.S.; Shit, P.K.; Maiti, R. Comparison of GIS-based interpolation methods for spatial distribution of soil organic carbon (SOC). J. Saudi Soc. Agric. Sci. 2018, 17, 114-126. [CrossRef]

29. Wong, K.L.; Brady, O.J.; Campbell, O.M.; Benova, L. Comparison of spatial interpolation methods to create high-resolution poverty maps for low-and middle-income countries. J. R. Soc. Interface 2018, 15, 20180252. [CrossRef] [PubMed]

30. Carleo, G.; Cirac, I.; Cranmer, K.; Daudet, L.; Schuld, M.; Tishby, N.; Vogt-Maranto, L.; Zdeborová, L. Machine learning and the physical sciences. Rev. Mod. Phys. 2019, 91, 045002. [CrossRef]

31. Liakos, K.G.; Busato, P.; Moshou, D.; Pearson, S.; Bochtis, D. Machine learning in agriculture: A review. Sensors 2018, 18, 2674 [CrossRef] [PubMed]

32. Zou, L.; Wang, L.; Lin, A.; Zhu, H.; Peng, Y.; Zhao, Z. Estimation of global solar radiation using an artificial neural network based on an interpolation technique in southeast China. J. Atmos. Sol.-Terr. Phys. 2016, 146, 110-122. [CrossRef]

33. Otake, R.; Kurima, J.; Goto, H.; Sawada, S. Deep Learning Model for Spatial Interpolation of Real-Time Seismic Intensity. Seismol. Soc. Am. 2020, 91, 3433-3443.

34. Tadić, J.M.; Ilić, V.; Biraud, S. Examination of geostatistical and machine-learning techniques as interpolators in anisotropic atmospheric environments. Atmos. Environ. 2015, 111, 28-38. [CrossRef]

35. Holloway, J.; Helmstedt, K.J.; Mengersen, K.; Schmidt, M. A decision tree approach for spatially interpolating missing land cover data and classifying satellite images. Remote Sens. 2019, 11, 1796. [CrossRef]

36. Neissi, L.; Golabi, M.; Gorman, J.M. Spatial interpolation of sodium absorption ratio: A study combining a decision tree model and GIS. Ecol. Indic. 2020, 117, 106611. [CrossRef]

37. Zhang, X.; Liu, G.; Wang, H.; Li, X. Application of a hybrid interpolation method based on support vector machine in the precipitation spatial interpolation of basins. Water 2017, 9, 760. [CrossRef]

38. Ma, J.; Ding, Y.; Cheng, J.C.; Jiang, F.; Wan, Z. A temporal-spatial interpolation and extrapolation method based on geographic Long Short-Term Memory neural network for PM2.5. J. Clean. Prod. 2019, 237, 117729. [CrossRef]

39. Rhee, J.; Im, J. Meteorological drought forecasting for ungauged areas based on machine learning: Using long-range climate forecast and remote sensing data. Agri. For. Meteorol. 2017, 237, 105-122. [CrossRef]

40. Azeez, O.S.; Pradhan, B.; Shafri, H.Z. Vehicular CO emission prediction using support vector regression model and GIS. Sustainability 2018, 10, 3434. [CrossRef]

41. Appelhans, T.; Mwangomo, E.; Hardy, D.R.; Hemp, A.; Nauss, T. Evaluating machine learning approaches for the interpolation of monthly air temperature at Mt. Kilimanjaro, Tanzania. Spat. Stat. 2015, 14, 91-113. [CrossRef] 
42. Leirvik, T.; Yuan, M. A Machine learning technique for spatial interpolation of solar radiation observations. Earth Space Sci. 2021, 8, e2020EA001527. [CrossRef]

43. Davies, M.M.; van der Laan, M.J. Optimal Spatial Prediction Using Ensemble Machine Learning. Int. J. Biostat. 2016, 12, 179-201. [CrossRef]

44. Silatsa, F.B.; Yemefack, M.; Tabi, F.O.; Heuvelink, G.B.; Leenaars, J.G. Assessing countrywide soil organic carbon stock using hybrid machine learning modelling and legacy soil data in Cameroon. Geoderma 2020, 367, 114260. [CrossRef]

45. Di Nunno, F.; Granata, F. Groundwater level prediction in Apulia region (Southern Italy) using NARX neural network. Environ. Res. 2020, 190, 110062. [CrossRef] [PubMed]

46. Alsumaiei, A.A. A nonlinear autoregressive modeling approach for forecasting groundwater level fluctuation in urban aqui-fers. Water 2020, 12, 820. [CrossRef]

47. Wunsch, A.; Liesch, T.; Broda, S. Forecasting groundwater levels using nonlinear autoregressive networks with exogenous input (NARX). J. Hydrol. 2018, 567, 743-758. [CrossRef]

48. Chang, F.J.; Chen, P.A.; Liu, C.W.; Liao, V.H.C.; Liao, C.M. Regional estimation of groundwater arsenic concentrations through systematical dynamic-neural modeling. J. Hydrol. 2013, 499, 265-274. [CrossRef]

49. Li, P.; Hua, P.; Gui, D.; Niu, J.; Pei, P.; Zhang, J.; Krebs, P. A comparative analysis of artificial neural networks and wavelet hybrid approaches to long-term toxic heavy metal prediction. Sci. Rep. 2020, 10, 1-15.

50. Wang, J.; Geng, Y.; Zhao, Q.; Zhang, Y.; Miao, Y.; Yuan, X.; Jin, Y.; Zhang, W. Water Quality Prediction of Water Sources Based on Meteorological Factors using the CA-NARX Approach. Environ. Model. Assess. 2021, 1-13.

51. Tzanis, C.G.; Alimissis, A.; Koutsogiannis, I. Addressing Missing Environmental Data via a Machine Learning Scheme. Atmosphere 2021, 12, 499. [CrossRef]

52. Du, P.; Bai, X.; Tan, K.; Xue, Z.; Samat, A.; Xia, J.; Li, E.; Su, H.; Liu, W. Advances of four machine learning methods for spatial data handling: A review. J. Geovis. Spat. Anal. 2020, 4, 1-25. [CrossRef]

53. Naprstek, T.; Smith, R. Applications of machine learning to the spatial interpolation of aeromagnetic data. In SEG International Exposition and Annual Meeting; OnePetro: Richardson, TX, USA, 2019.

54. Stahl, K.; Moore, R.D.; Floyer, J.A.; Asplin, M.G.; McKendry, I.G. Comparison of approaches for spatial interpolation of daily air temperature in a large region with complex topography and highly variable station density. Agric. For. Meteorol. 2006, 139, 224-236. [CrossRef]

55. Salvacion, A.R.; Magcale-Macandog, D.B. Spatial analysis of human population distribution and growth in Marinduque Island, Philippines. J. Mar. Isl. Cult. 2015, 4, 27-33. [CrossRef]

56. Fesalbon, R.M.A.; Blanco, A.C. Hydropower DAM Site Selection and Visualization Using GIS and RS Techniques: A Case of Marinduque, Philippines. Int. Arch. Photogramm. Remote Sens. Spat. Inf. Sci. 2019, 42, 207-214. [CrossRef]

57. Tolentino, P.L.M.; Poortinga, A.; Kanamaru, H.; Keesstra, S.; Maroulis, J.; David, C.P.C.; Ritsema, C.J. Projected impact of climate change on hydrological regimes in the Philippines. PLoS ONE 2016, 11, e0163941. [CrossRef]

58. Salvacion, A.R. Mapping land limitations for agricultural land use planning using fuzzy logic approach: A case study for Marinduque Island, Philippines. GeoJournal 2021, 86, 915-925. [CrossRef]

59. Senoro, D.B.; De Jesus, K.L.; Chyan, J.M.; Lamac, M.R.L.; Bonifacio, P.B.; Natal, P.; Ney, F.P.; Yanuaria, C.A.S. Spatial Distribution of Hydrogeological Attributes in the Small Island Province of the Philippines: A Tool for Risk Analysis and Reduction Strategy. In Proceedings of the Climate Smart and Disaster Resilient International Conference 2020, Virtual Platform, 26 October 2020. in press.

60. Coumans, C. Whose development? Mining, local resistance, and development agendas. In Governance Ecosystems; Palgrave Macmillan: London, UK, 2011; pp. 114-132.

61. Dacre, C.K.; Mercer, K.G.; Smith, F.G.F.; McParland, M.A.; Morin, R. The use of satellite-based remote sensing methods to assess the changes in the environmental impacts from the Marcopper disaster on Marinduque Island, Philippines. In Proceedings of the 11th International Conference on Mine Closure, Perth, Australia, 15-17 March 2016; Australian Center for Geomechanics: Crawley, Western Australia, Australia, 2016; pp. 339-352.

62. Holden, W.N.; Daniel Jacobson, R. Ecclesial opposition to nonferrous metals mining in the Philippines: Neoliberalism encounters liberation theology. Asian Stud. Rev. 2007, 31, 133-154. [CrossRef]

63. Abdel-Satar, A.M.; Al-Khabbas, M.H.; Alahmad, W.R.; Yousef, W.M.; Alsomadi, R.H.; Iqbal, T. Quality assessment of groundwater and agricultural soil in Hail region, Saudi Arabia. Egypt. J. Aquat. Res. 2017, 43, 55-64. [CrossRef]

64. Asare-Donkor, N.K.; Boadu, T.A.; Adimado, A.A. Evaluation of groundwater and surface water quality and human risk assessment for trace metals in human settlements around the Bosomtwe Crater Lake in Ghana. SpringerPlus 2016, 5, 1812. [CrossRef]

65. Jang, M.; Lee, H.J.; Shim, Y. Rapid removal of fine particles from mine water using sequential processes of coagulation and flocculation. Environ. Technol. 2010, 31, 423-432. [CrossRef]

66. Corales-Ultra, O.G.; Peja, R.P., Jr.; Casas, E.V., Jr. Baseline study on the levels of heavy metals in seawater and macroalgae near an abandoned mine in Manicani, Guiuan, Eastern Samar, Philippines. Mar. Pollut. Bull. 2019, 149, 110549. [CrossRef]

67. Liu, J.; Wang, P.; Wang, C.; Qian, J.; Hou, J. Heavy metal pollution status and ecological risks of sediments under the influence of water transfers in Taihu Lake, China. Environ. Sci. Pollut. Res. 2017, 24, 2653-2666. [CrossRef] 
68. Ma, L.; Wang, L.; Tang, J.; Yang, Z. Arsenic speciation and heavy metal distribution in polished rice grown in Guangdong Province, Southern China. Food Chem. 2017, 233, 110-116. [CrossRef]

69. Arslan, H.; Turan, N.A. Estimation of spatial distribution of heavy metals in groundwater using interpolation methods and multivariate statistical techniques; its suitability for drinking and irrigation purposes in the Middle Black Sea Region of Turkey. Environ. Monit. Assess. 2015, 187, 1-13. [CrossRef]

70. Yalcin, F. Data analysis of beach sands' chemical analysis using multivariate statistical methods and heavy metal distribution maps: The case of Moonlight Beach sands, Kemer, Antalya, Turkey. Symmetry 2020, 12, 1538. [CrossRef]

71. Narany, T.S.; Ramli, M.F.; Aris, A.Z.; Sulaiman, W.N.A.; Fakharian, K. Spatiotemporal variation of groundwater quality using integrated multivariate statistical and geostatistical approaches in Amol-Babol Plain, Iran. Environ. Monit. Assess. 2014, 186, 5797-5815. [CrossRef]

72. Dai, L.; Wang, L.; Li, L.; Liang, T.; Zhang, Y.; Ma, C.; Xing, B. Multivariate geostatistical analysis and source identification of heavy metals in the sediment of Poyang Lake in China. Sci. Total Environ. 2018, 621, 1433-1444. [CrossRef]

73. Schober, P.; Boer, C.; Schwarte, L.A. Correlation coefficients: Appropriate use and interpretation. Anesth. Analg. 2018, 126, 1763-1768. [CrossRef]

74. Sarkar, A.; Pandey, P. River water quality modelling using artificial neural network technique. Aquat. Procedia 2015, 4, 1070-1077. [CrossRef]

75. Kucukoglu, I.; Atici-Ulusu, H.; Gunduz, T.; Tokcalar, O. Application of the artificial neural network method to detect defective assembling processes by using a wearable technology. J. Manuf. Syst. 2018, 49, 163-171. [CrossRef]

76. Babu, D.; Thangarasu, V.; Ramanathan, A. Artificial neural network approach on forecasting diesel engine characteristics fuelled with waste frying oil biodiesel. Appl. Energy 2020, 263, 114612. [CrossRef]

77. Mammadli, S. Financial time series prediction using artificial neural network based on Levenberg-Marquardt algorithm. Procedia Comput. Sci. 2017, 120, 602-607. [CrossRef]

78. Rinchon, J.P.M.; Concha, N.C.; Calilung, M.G.V. Reinforced concrete ultimate bond strength model using hybrid neural networkgenetic algorithm. In Proceedings of the 2017 IEEE 9th International Conference on Humanoid, Nanotechnology, Information Technology, Communication and Control, Environment and Management (HNICEM), Manila, Philippines, 1-3 December 2017; IEEE: New York, NY, USA, 2017; pp. 1-6.

79. You, L.; Tan, Q.; Kang, Y.; Xu, C.; Lin, C. Reconstruction and prediction of capillary pressure curve based on Particle Swarm Optimization-Back Propagation Neural Network method. Petroleum 2018, 4, 268-280. [CrossRef]

80. Ozerdem, O.C.; Olaniyi, E.O.; Oyedotun, O.K. Short term load forecasting using particle swarm optimization neural network. Procedia Comput. Sci. 2017, 120, 382-393. [CrossRef]

81. Chatterjee, S.; Sarkar, S.; Hore, S.; Dey, N.; Ashour, A.S.; Balas, V.E. Particle swarm optimization trained neural network for structural failure prediction of multistoried RC buildings. Neural Comput. Appl. 2017, 28, 2005-2016. [CrossRef]

82. Alnaqi, A.A.; Moayedi, H.; Shahsavar, A.; Nguyen, T.K. Prediction of energetic performance of a building integrated photovoltaic/thermal system thorough artificial neural network and hybrid particle swarm optimization models. Energy Convers. Manag. 2019, 183, 137-148. [CrossRef]

83. Malik, S.; Kim, D. Prediction-learning algorithm for efficient energy consumption in smart buildings based on particle regeneration and velocity boost in particle swarm optimization neural networks. Energies 2018, 11, 1289. [CrossRef]

84. Qi, C.; Fourie, A.; Chen, Q. Neural network and particle swarm optimization for predicting the unconfined compressive strength of cemented paste backfill. Constr. Build. Mater. 2018, 159, 473-478. [CrossRef]

85. Golafshani, E.M.; Rahai, A.; Sebt, M.H.; Akbarpour, H. Prediction of bond strength of spliced steel bars in concrete using artificial neural network and fuzzy logic. Constr. Build. Mater. 2012, 36, 411-418. [CrossRef]

86. Zheng, Z.; Ma, X.; Ma, Y.; Dong, G. Wave estimation within a port using a fully nonlinear Boussinesq wave model and artificial neural networks. Ocean Eng. 2020, 216, 108073. [CrossRef]

87. Wu, S.; McLean, K.A.; Harris, T.J.; McAuley, K.B. Selection of optimal parameter set using estimability analysis and MSE-based model-selection criterion. Int. J. Adv. Mechatron. Syst. 2011, 3, 188-197. [CrossRef]

88. Ranković, V.; Radulović, J.; Radojević, I.; Ostojić, A.; Čomić, L. Neural network modeling of dissolved oxygen in the Gruža reservoir, Serbia. Ecol. Model. 2010, 221, 1239-1244. [CrossRef]

89. Senoro, D.B.; De Jesus, K.L.M.; Yanuaria, C.A.; Bonifacio, P.B.; Manuel, M.T.; Wang, B.N.; Kao, C.C.; Wu, T.N.; Ney, F.P.; Natal, P. Rapid site assessment in a small island of the Philippines contaminated with mine tailings using ground and areal technique: The environmental quality after twenty years. IOP Conf. Ser. Earth Environ. Sci. 2019, 351, 012022. [CrossRef]

90. Ohmer, M.; Liesch, T.; Goeppert, N.; Goldscheider, N. On the optimal selection of interpolation methods for groundwater contouring: An example of propagation of uncertainty regarding inter-aquifer exchange. Adv. Water Resour. 2017, 109, 121-132. [CrossRef]

91. Aguilar, F.J.; Agüera, F.; Aguilar, M.A.; Carvajal, F. Effects of terrain morphology, sampling density and interpolation methods on grid DEM accuracy. Photogramm. Eng. Remote Sens. 2005, 71, 805-816. [CrossRef]

92. Yilmaz, H.M. The effect of interpolation methods in surface definition: An experimental study. Earth Surf. Process. Landf J. Br. Geomorphol. Res. Group. 2007, 32, 1346-1361. [CrossRef]

93. Eldeiry, A.A.; Garcia, L.A. Comparison of ordinary kriging, regression kriging, and cokriging techniques to estimate soil salinity using LANDSAT images. J. Irrig. Drain. Eng. 2010, 136, 355-364. [CrossRef] 
94. Roznik, M.; Porth, C.B.; Boyd, M.; Roznik, K. Improving agricultural microinsurance by applying universal kriging and generalized additive models for interpolation of mean daily temperature. Geneva Pap. Risk Insur.-Issues Pract. 2019, 44, 446-480. [CrossRef]

95. Mirzaei, R.; Sakizadeh, M. Comparison of interpolation methods for the estimation of groundwater contamination in AndimeshkShush Plain, Southwest of Iran. Environ. Sci. Pollut. Res. 2016, 23, 2758-2769. [CrossRef]

96. Türker, T.; Bayrak, Y. An interpolation applied with barriers modeling to predictions of earthquake occurrences using Kernel Smoothing and Diffusion Kernel methods in the Marmara Sea, Turkey. In Proceedings of the 2nd International Symposium on Natural Hazards and Disaster Management, Sakarya, Turkey, 4-6 May 2018.

97. Plouffe, C.C.; Robertson, C.; Chandrapala, L. Comparing interpolation techniques for monthly rainfall mapping using multiple evaluation criteria and auxialiary data sources: A case study of Sri Lanka. Environ. Model. Softw. 2015, 67, 57-71. [CrossRef]

98. Xie, Y.; Chen, T.B.; Lei, M.; Yang, J.; Guo, Q.J.; Song, B.; Zhou, X.Y. Spatial distribution of soil heavy metal pollution estimated by different interpolation methods: Accuracy and uncertainty analysis. Chemosphere 2011, 82, 468-476. [CrossRef]

99. Qiao, P.; Lei, M.; Yang, S.; Yang, J.; Guo, G.; Zhou, X. Comparing ordinary kriging and inverse distance weighting for soil as pollution in Beijing. Environ. Sci. Pollut. 2018, 25, 15597-15608. [CrossRef]

100. Agarin, C.J.M.; Mascareñas, D.R.; Nolos, R.; Chan, E.; Senoro, D.B. Transition Metals in Freshwater Crustaceans, Tilapia, and Inland Water: Hazardous to the Population of the Small Island Province. Toxics 2021, 9, 71. [CrossRef]

101. Manikandan, E.; Rajmohan, N.; Anbazhagan, S. Monsoon impact on groundwater chemistry and geochemical processes in the shallow hard rock aquifer. Catena 2020, 195, 104766. [CrossRef]

102. Kumar, P.S.; Delson, P.D.; Babu, P.T. Appraisal of heavy metals in groundwater in Chennai city using a HPI model. Bull. Environ. Contam. Toxicol. 2012, 89, 793. [CrossRef]

103. Mansouri, B.; Salehi, J.; Etebari, B.; Moghaddam, H.K. Metal concentrations in the groundwater in Birjand flood plain, Iran. Bull. Environ. Contam. Toxicol. 2012, 89, 138-142. [CrossRef]

104. Kirschke, S.; Avellán, T.; Bärlund, I.; Bogardi, J.J.; Carvalho, L.; Chapman, D.; Dickens, C.W.S.; Irvine, K.; Lee, S.; Mehner, T.; et al. Capacity challenges in water quality monitoring: Understanding the role of human development. Environ. Monit. Assess. 2020, 192, 1-16. [CrossRef] [PubMed]

105. Xu, T.; Liu, Y.; Tang, L.; Liu, C. Improvement of Kriging interpolation with learning kernel in environmental variables study. Int. J. Prod. Res. 2020, 1-14. [CrossRef]

106. Li, J. Predicting the spatial distribution of seabed gravel content using random forest, spatial interpolation methods and their hybrid methods. In Proceedings of the International Congress on Modelling and Simulation (MODSIM), Adelaide, Australia, 1-6 December 2013; pp. 1-6.

107. Bai, T.; Tahmasebi, P. Accelerating geostatistical modeling using geostatistics-informed machine Learning. Comput. Geosci. 2021, 146, 104663. [CrossRef]

108. Zhou, B.; Zhang, X.G.; Wang, F.; Wang, R.C. Soil organic matter mapping by decision tree modeling. Pedosphere 2005, 15, 103-109.

109. Sauter, T.; Weitzenkamp, B.; Schneider, C. Spatio-temporal prediction of snow cover in the Black Forest mountain range using remote sensing and a recurrent neural network. Int. J. Climatol. 2010, 30, 2330-2341. [CrossRef]

110. Li, J.; Heap, A.D.; Potter, A.; Daniell, J.J. Application of machine learning methods to spatial interpolation of environmental variables. Environ. Monit. Softw. 2011, 26, 1647-1659. [CrossRef] 